\title{
A taxonomic review of the ant genus Megalomyrmex Forel (Hymenoptera: Formicidae) in Central America
}

\author{
JOHN T. LONGINO \\ The Evergreen State College, Olympia WA 98505 USA. E-mail: longinoj@evergreen.edu
}

\begin{abstract}
The ant genus Megalomyrmex is known only from the Neotropics, where some of the species are specialized parasites or predators of Attini. A taxonomic review and a key to species is provided for the fauna of Central America and southern Mexico. The following new species are described: M. adamsae, M. mondaboroides, M. nocarina, M. reina.
\end{abstract}

Key words: Myrmicinae, Attini, Neotropics

\section{Introduction}

The genus Megalomyrmex Forel is a distinct Neotropical taxon with 34 described species (Brandão 1990, 2003). It is difficult to characterize morphologically. Bolton (2003) placed it in the tribe Solenopsidini, but with multiple exceptions to the diagnostic characters for the tribe. The tribal characters include a bicarinate clypeus and a median clypeal seta. Most Megalomyrmex species have a smoothly convex clypeus with no trace of the bicarinate condition, and most have abundant clypeal setae with no distinct or differentiated median seta. In Bolton's (1994) key to genera, Megalomyrmex keys in multiple places because of variability in mandibular dentition. Nevertheless, the genus has a distinctive habitus: the antenna is 12-segmented with a 3-segmented club; the general integument is smooth and shiny without coarse sculpture or dull areas; the promesonotum is evenly arched, without promesonotal groove; the propodeum is usually smoothly curved between dorsal and posterior faces, at most with blunt, broadbased tubercles, and never with spines; and the hind tibial spur is simple. In short, the workers look like a Solenopsis with Pheidole antennae. The mandibular dentition varies from a simple set of 5 similar teeth on the masticatory margin, gradually diminishing in size basally, to a condition with 2 large apical teeth followed by up to 12 small denticles.

Although widespread in the Neotropics, from southern Mexico to northern Argentina, Megalomyrmex species are never abundant. They occur in low to middle elevation wet to dry forest habitats. Some species are free-living with large diffuse nests in the soil (e.g. modestus) or small nests in dead wood (e.g. drifti) (Brandão 1990, 2003). Others are specialized social parasites or predators of Attini (e.g. mondabora, symmetochus, wettereri; Wheeler 1925, Weber 1941, Kempf \& Brown 1968, Adams et al. 2000, Adams \& Longino 2007). Some species have unusual alkaloids (Jones et al. 1991a; Jones et al.1991b; Jones et al. 1999).

Brandão (1990) was the last comprehensive revision of the genus, with updates and additional species descriptions by Fernández and Baena (1997) and Brandão (2003). Coverage of the Central American fauna was limited due to the paucity of collections from the region. Since then, large-scale biodiversity inventory projects in Costa Rica (Project ALAS, TEAM) and elsewhere in Central America (Project LLAMA) have greatly increased the number of specimens available for study. In addition, Rachelle Adam's work on the attine-associated Megalomyrmex of Panama and Costa Rica has yielded abundant new material for study and evidence for cryptic species. The new material and Adam's discoveries allow an update and key to the Megalomyrmex fauna found from Panama to Mexico. 


\section{Terminology and measurements}

The foramen on the posterior face of the propodeum, into which the petiole inserts, may be delimited by a distinct semicircular dorsal carina. The presence or absence of this carina varies among species. Brandão (1990) used the term "epipetiolar carina" for this structure; here it is referred to as the "foraminal carina."

The following measurements and indices are reported:

HL: head length; in full-face view, maximum length of head, from line tangent to anteriormost projection of head capsule or clypeus to line tangent to posteriormost projection of posterior margin of head (including occipital carina, if visible).

HW: head width; in full-face view, maximum width of head capsule including eyes if they protrude beyond margins of head.

SL: scape length; length of scape shaft from apex to basal flange, not including basal condyle and neck.

EL: eye length; maximum length of compound eye, with head oriented to maximize length (i.e., not full-face view).

ML: mesosoma length; in lateral view, distance from base of anterior face of pronotum (at inflection point between downward-sloping anterior face and flange-like anteriormost projection of pronotum [the latter extending to foramen and usually partially hidden by head capsule]) to posteriormost extension of propodeal lobes.

CI: cephalic index; 100*HW/HL.

SI: scape index; $100 *$ SL/HL.

\section{Methods}

Observations were made at $63 x$ magnification with a Leica MZ12.5 dissecting microscope. Measurements were made with a dual-axis micrometer stage with output in increments of $0.001 \mathrm{~mm}$. However, variation in specimen orientation, alignment of crosshairs with edges of structures, and interpretation of structure boundaries resulted in measurement accuracy to the nearest 0.02 to $0.005 \mathrm{~mm}$, depending on sharpness of the defined boundary. All measurements are presented in $\mathrm{mm}$.

All holotypes and paratypes associated with the new species described here have unique specimen-level identifiers ("specimen codes") affixed to each pin. When multiple specimens are on the same pin, they share a single specimen code. The specimen codes are listed for type material. Specimen codes should not be confused with collection codes, which are associated with particular collection events. When reported, collection codes follow the collector. Specimen collection data are derived from a specimen database and are not direct transcriptions of labels. Images of holotypes, distribution maps, and all specimen data on which this paper is based are available on AntWeb (www.antweb.org).

\section{Repositories}

Collections are referred to by the following acronyms, which follow the Insect and Spider Collections of the World website (http://hbs.bishopmuseum.org/codens/) and/or the Registry of Biological Repositories (http:// www.biorepositories.org/):

CAS California Academy of Sciences, San Francisco, CA, USA.

INBC Instituto Nacional de Biodiversidad, Costa Rica.

LACM Los Angeles County Museum of Natural History, Los Angeles, CA, USA.

MCSN Museo Civico de Storia Naturale "Giacomo Doria," Genoa, Italy.

MCZ Museum of Comparative Zoology, Cambridge, MA, USA.

MZSP Museu de Zoologia da Universidade de São Paulo, São Paulo, Brazil.

UCD Bohart Museum of Entomology, University of California, Davis, CA, USA.

USNM National Museum of Natural History, Washington, DC, USA. 


\section{Synopsis of the genus Megalomyrmex Forel 1885}

Megalomyrmex Forel, 1885: 371. Type-species: Megalomyrmex leoninus Forel, by monotypy. [Type-species not Formica bituberculata Fabricius, unjustified subsequent designation by Wheeler, W.M. 1911: 167.]

Megalomyrmex in Myrmicinae: Dalla Torre, 1893: 71.

Megalomyrmex in Myrmicinae, Myrmicini: Emery, 1895: 769; Forel, 1899: 57; Ashmead, 1905: 383; Wheeler, W.M. 1910: 139.

Megalomyrmex in Myrmicinae, Pheidolini: Kusnezov, 1952: 10 (in key).

Megalomyrmex in Myrmicinae, Megalomyrmex genus group: Ettershank, 1966: 81; in Solenopsis genus group: Bolton, 1987: 271; Brandão, 1990: 412.

Megalomyrmex in Myrmicinae, Megalomyrmecini: Dlussky \& Fedoseeva, 1988: 80.

Megalomyrmex in Myrmicinae, Solenopsidini: Emery, 1914: 41 [subtribe Monomoriini]; Forel, 1917: 243; Emery, 1922: 189; Wheeler, W.M. 1922: 663; Kusnezov, 1957: 268; Kusnezov, 1962: 160; Kusnezov, 1964: 61; Hölldobler \& Wilson, 1990: 16; Jaffe, 1993: 10; Bolton, 1994: 106.

Wheelerimyrmex Mann, 1922: 29 [as subgenus of Megalomyrmex]. Type-species: Megalomyrmex silvestrii, by original designation. Junior synonym of Megalomyrmex: Ettershank, 1966: 101; Brandão, 1990: 415.

Cepobroticus Wheeler, W.M. 1925: 168 [as subgenus of Megalomyrmex]. Type-species: Megalomyrmex (Cepobroticus) symmetochus, by monotypy. Junior synonym of Megalomyrmex: Ettershank, 1966: 101; Brandão, 1990: 415.

\section{Taxonomic synopsis of Central American Megalomyrmex}

Megalomyrmex adamsae new species

Megalomyrmex drifti Kempf, 1961

Megalomyrmex foreli Emery, 1890

= Megalomyrmex latreillei Emery, 1890

Megalomyrmex incisus M. R. Smith, 1947

Megalomyrmex miri Brandão, 1990

Megalomyrmex modestus Emery, 1896

Megalomyrmex mondabora Brandão, 1990

Megalomyrmex mondaboroides new species

Megalomyrmex nocarina new species

Megalomyrmex reina new species

Megalomyrmex silvestrii Wheeler, 1909

= Megalomyrmex brasiliensis Borgmeier, 1930

= Megalomyrmex langi Wheeler, 1925

= Megalomyrmex misionensis Santschi, 1936

= Megalomyrmex sjostedti Wheeler, 1925

= Megalomyrmex wheeleri Weber, 1940

Megalomyrmex symmetochus Wheeler, 1925

Megalomyrmex wallacei Mann, 1916

Megalomyrmex wettereri Brandão, 2003

\section{Key to the species of Megalomyrmex}

This key covers the region from central Panama to the northern limit of the genus in Mexico. Megalomyrmex reina, known only from queens, is not keyed.

1 Mandibles with 5 distinct teeth, apical tooth largest, proximal tooth next largest, remaining three teeth the smallest and subequal in size (Fig. 1A); ML greater than $1 \mathrm{~mm}$

- Mandibles with a large apical and subapical tooth, and a series of usually 4 or more smaller basal teeth (Figs 1B-F); if only 3 basal teeth (some specimens of drifti), then ML less than $1 \mathrm{~mm}$... 
A
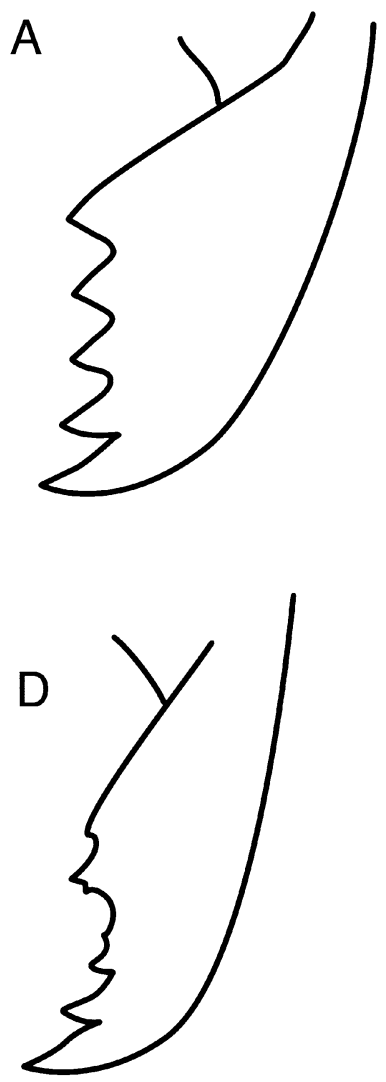

B

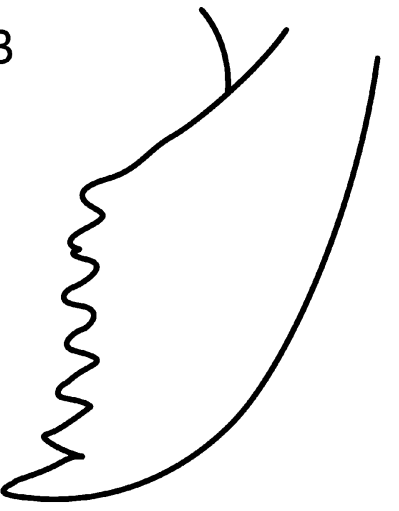

E

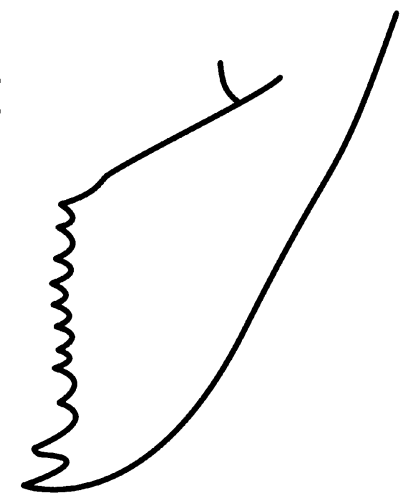

C
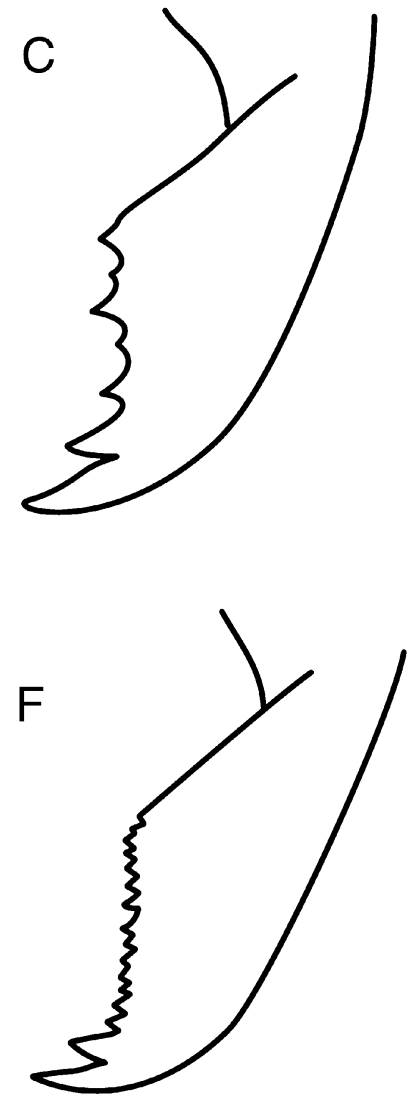

FIGURE 1. Variation in mandibular dentition among (A) foreli, (B) symmetochus, (C) drifti, (D) incisus, (E) mondaboroides, and (F) silvestrii.

2 Dorsal surface of mandible striate; occipital carina not visible in face view. Costa Rica to Venezuela

M. modestus Emery

Dorsal surface of mandible largely smooth with large piligerous punctures; occipital carina visible or not.

3 Metanotal groove very deep and broad; propodeum broadly curved, without differentiated dorsal and posterior faces (Fig. 2A); ventral margin of postpetiole protruding, evenly convex, without anteroventral spine. Costa Rica to Guianas, Amazonian Brazil

M. wallacei Mann

- Metanotal groove less strongly impressed; propodeum with differentiated dorsal and posterior faces, and often with pair of blunt tubercles (Fig. 2B); ventral margin of postpetiole flat, sloping anteriorly, anterior margin often terminating in long, needle-like spine. Costa Rica south to Andean regions of Colombia, Ecuador, and northern Peru.....

M. foreli Emery
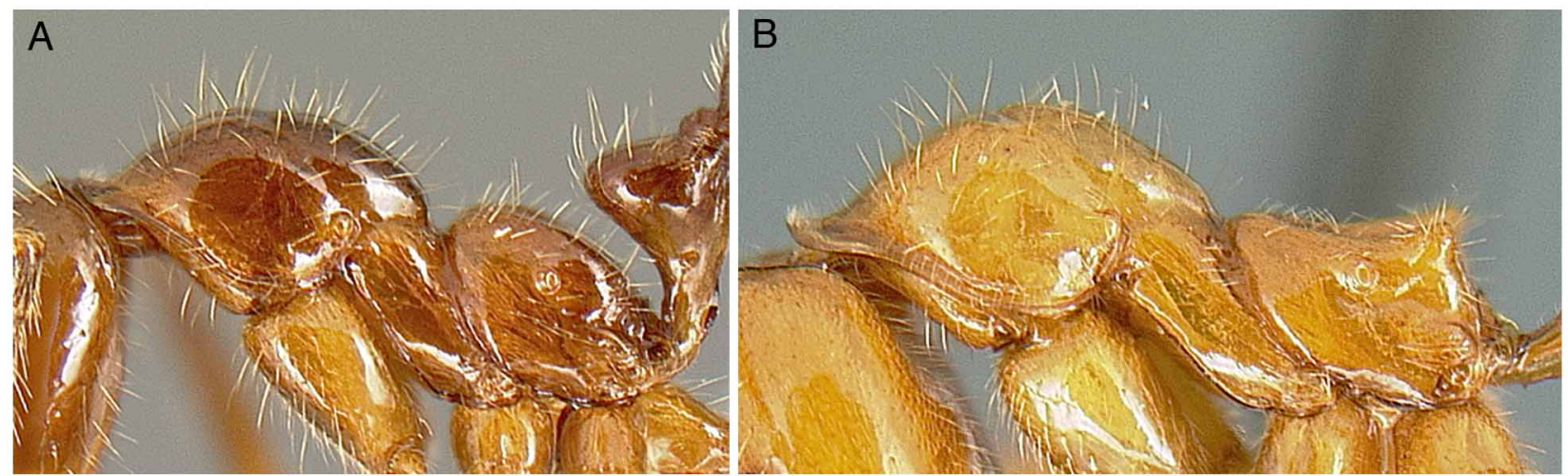

FIGURE 2. Mesosomal profile of (A) wallacei and (B) foreli.

4 Dorsal surface of mandible coarsely striate; color orange brown; body covered with dense, yellow pilosity 5

- Dorsal surface of mandible entirely smooth or smooth distally and striate only at base; color and pilosity various... 6 
5 Dorsal pilosity thin and flexuous (Fig. 3A); scape relatively short (SI 90-93); ventral keel of petiole Y-shaped, anterior carina splitting into two and forming two diverging posterior arms (Fig. 3C). Costa Rica and Panama, possibly further south into South America M. symmetochus Wheeler

- $\quad$ Dorsal pilosity coarse and stiff (Fig. 3B); scape relatively long (SI 94-98); ventral keel of petiole interrupted, a single median carina anteriorly, two short subparallel carinae posteriorly (Fig. 3D). Panama, possibly further south into South America

M. adamsae new species

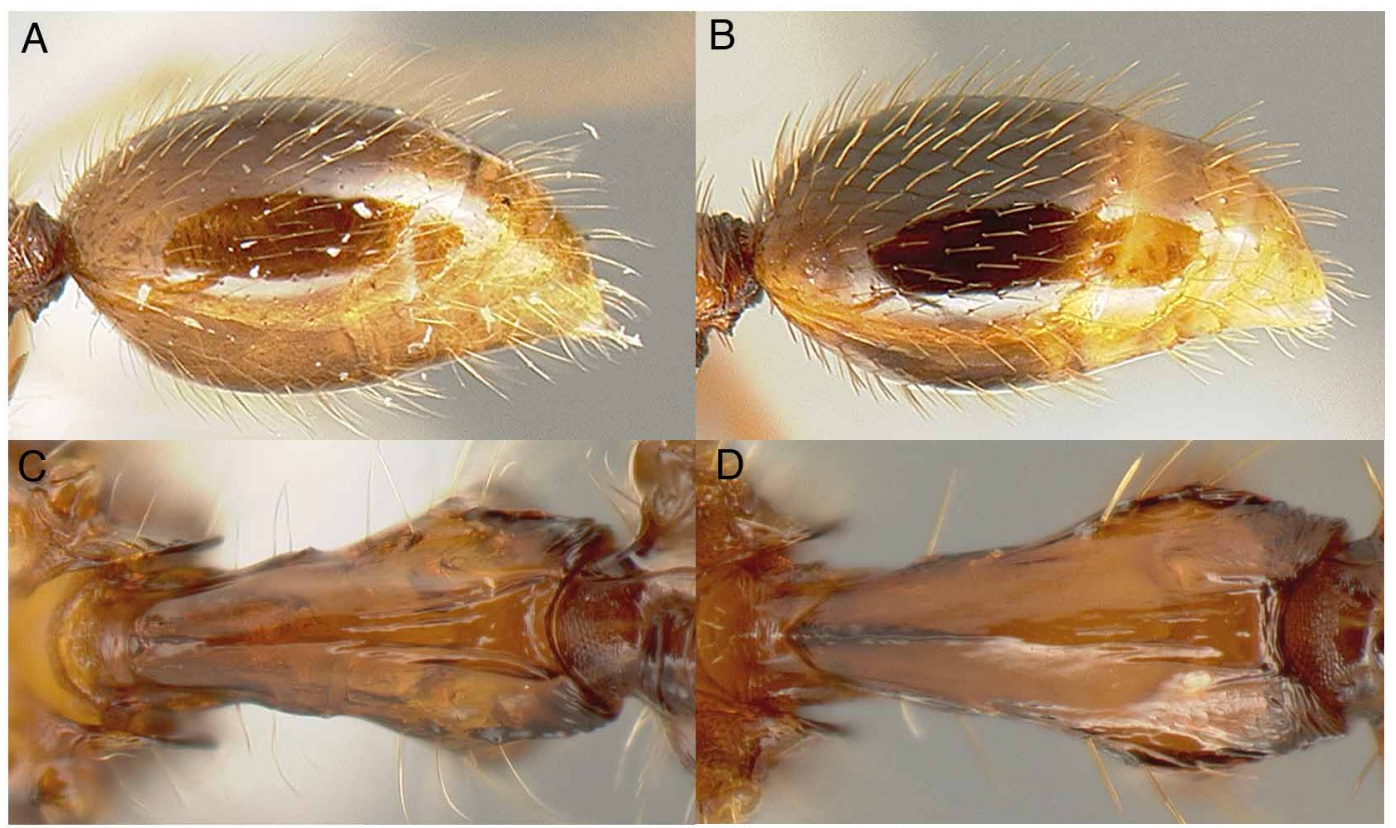

FIGURE 3. Dorsal pilosity of (A) symmetochus and (B) adamsae. Ventral petiolar keel of (C) symmetochus and (D) adamsae.

6 Eyes very small, $<6$ facets across greatest diameter; color yellow orange.

- $\quad$ Eyes larger, >10 facets across greatest diameter; color usually red brown to black (silvestrii specimens may occasionally be pale brown).

.88

7 Foraminal carina (on the posterior face of the propodeum) complete (Fig. 5B); subpetiolar process with a transversly sculptured flange. Costa Rica.

M. miri Brandão

- Foraminal carina incomplete (Fig. 5A); subpetiolar process a laterally compressed tooth, not a transverse flange. Costa Rica and Panama .................................................................................................... M. wettereri Brandão

8 Petiolar node in lateral view robust, subtriangular, with anterior face straight, steeper than posterior face (Fig. 4A); scape short (SI 92); mandible subfalcate, 4-7 basal teeth, often with the second tooth from the base larger than the flanking teeth (Fig. 1D). Southern Mexico south to central Brazil and Peru, absent in Costa Rica

M. incisus M.R. Smith

Petiolar node thinner, anterior face slightly concave, less steep than posterior face (Fig. 4B); scape length various (SL 75-140); mandible more triangular, not falcate, basal teeth of more uniform size, gradually increasing in size apically, or rarely with second from base slightly larger than others (Figs 1C, E, F)

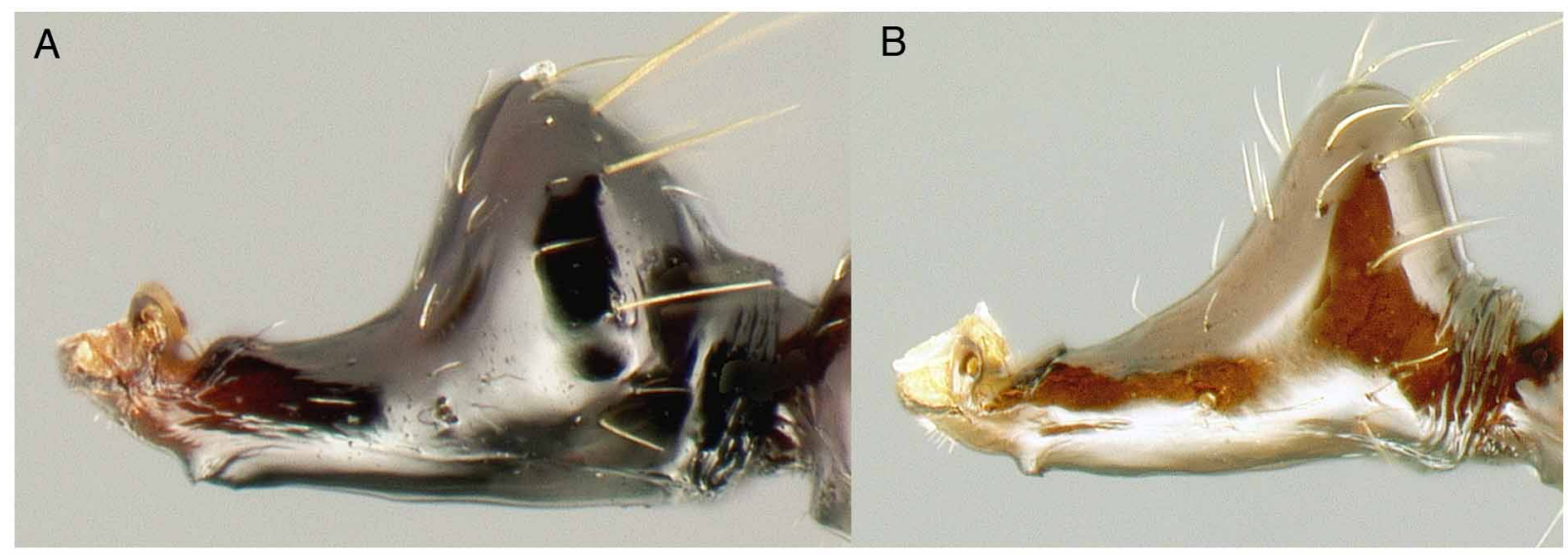

FIGURE 4. Lateral view of petiole of (A) incisus and (B) drifti. 
9 Scape not or barely surpassing vertex margin (SI 79-95); HW < $0.60 \mathrm{~mm}$; mandible with 3-5 small teeth proximal to larger distal pair (Fig. 1C); clypeus usually with pair of longitudinal carinae. Southern Mexico to southern Brazil M. drifti Kempf

- $\quad$ Scape distinctly surpassing vertex margin (SI > 95); HW > $0.60 \mathrm{~mm}$; mandible with five or more teeth proximal to distal pair (Figs 1E, F)

10 Mandible with series of 12 or more minute teeth proximal to distal pair (Fig. 1E); median portion of clypeus protruding and the anterior margin of clypeus recessed, such that in face view the median portion of the clypeus partially obscures the anterior margin; scape long (SI 115-120). Southern Mexico to northern Argentina...

M. silvestrii Wheeler

- Mandible with series of 7-10 teeth proximal to distal pair (Fig. 1F); clypeus not protruding, anteromedian margin visible in face view; scape length variable.

11

11 Foraminal carina incomplete, absent dorsally (Fig. 5A); anterior clypeal margin more produced and subangular, not evenly rounded (Fig. 5C); scape relatively short (SI < 103). Costa Rica M. nocarina new species

- $\quad$ Foraminal carina complete (Fig. 5B); anterior clypeal margin evenly rounded (Fig. 5D); scape relatively long (SI > 105)

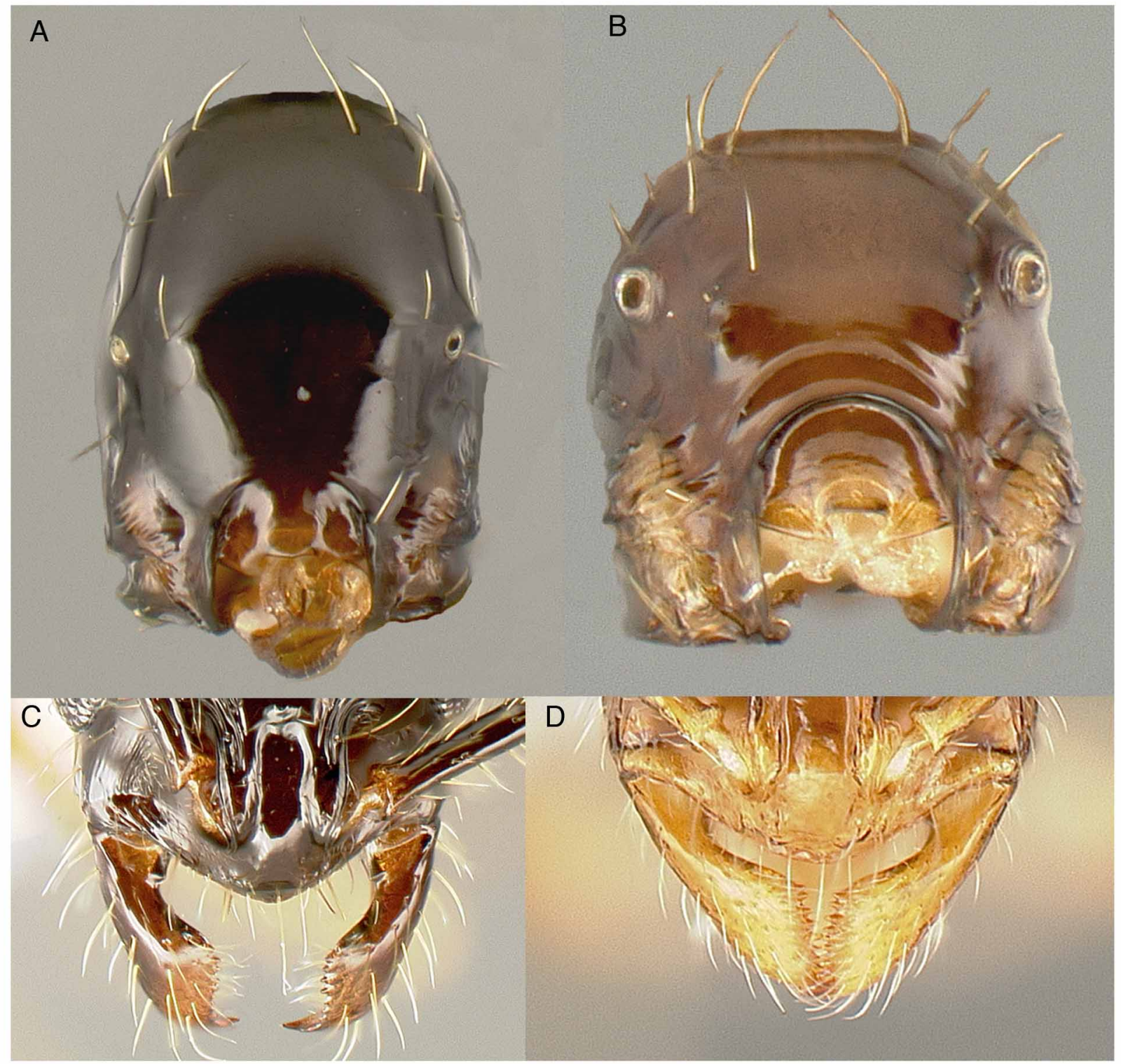

FIGURE 5. Foraminal carina (viewing posterior face of propodeum) of (A) nocarina and (B) mondaboroides. The foraminal carina is a distinct, elevated rim around the foramen in the posterior face of the propodeum, above the insertion of the petiole. It varies in completeness and may be absent dorsally, as in nocarina. Anterior clypeal margin of (C) nocarina and (D) mondaboroides. 
12 Scape relatively long (SI > 120); juncture of dorsal and posterior face of propodeum evenly convex (Fig. 6A); occipital carina relatively more developed (Fig. 6A); for most collections, basal tooth on the masticatory margin of the mandible similar in size to the more distal teeth, such that the juncture of the basal and masticatory margins forms a well-defined angle (M. mondabora holotype shows contrasting condition found in M. mondaboroides). Costa Rica

M. mondabora Brandão

- $\quad$ Scape relatively short (SI < 114); juncture of dorsal and posterior face of propodeum moderately depressed, flat to slightly concave (Fig. 6B); occipital carina relatively less developed (Fig. 6B); basal tooth on mandible smaller than more distal teeth, such that the basal and masticatory margin have a more rounded juncture. Costa Rica and Panama, possibly further south into Ecuador, Brazil ..... M. mondaboroides new species

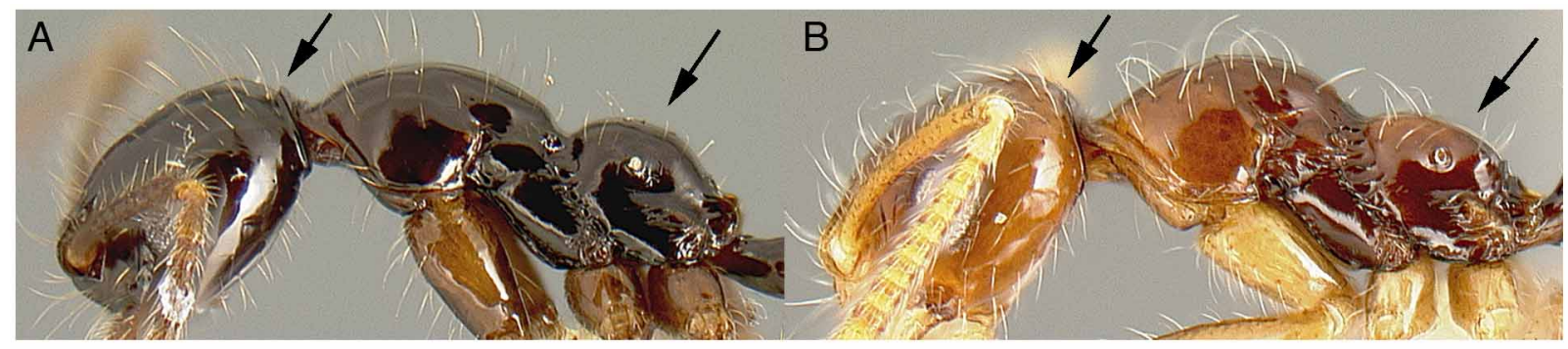

FIGURE 6. Contrasting propodeal shape and occipital carina of (A) mondabora and (B) mondaboroides.

\section{Species Accounts}

\section{Megalomyrmex adamsae Longino, new species}

(Figs 3B, 3D, 7A-H)

Type material. Holotype worker. Panama, Panama: Pipeline Rd., 4E heading N, 9.16000 N $79.74490^{\circ} \mathrm{W}, \pm 20 \mathrm{~m}$, 50 m, 29 Sep 1999 (R. Adams\#RMMA990929-01) [MCZ, unique specimen identifier CASENT0613258]. Paratypes: Same data as holotype, 1 worker [CAS, CASENT0613265], 4 workers [USNM, USNMENT00692982, USNMENT00693017, USNMENT00693018]; same data as holotype except \#RMMA990929-06, 1 male [MCZ, CASENT0613259], 1 male [CAS, CASENT0613266], 3 workers, 1 dealate queen, 2 alate queens [USNM, USNMENT00693010, USNMENT00693011, USNMENT00693012, USNMENT00692981].

\section{Geographic range. Panama.}

Diagnosis. Worker differing from M. symmetochus as follows: (1) setae on the mesosomal and gastral dorsum relatively stout and stiff (Fig. 3B); (2) scape relatively long (SI 94-98 vs. 90-93 in symmetochus); (3) ventral keel of petiole fading posteriorly, not connected to the two short subparallel carinulae at posterior margin (Fig. 3D), vs. ventral keel Y-shaped, splitting posteriorly to form two divergent carinulae at posterior margin (Fig. 3C).

Description. Worker. Measurements (holotype): HW 0.846, HL 0.898, SL 0.885, EL 0.257, ML 1.287, CI 94, SI 99.

Measurements (n=6): HW 0.816-0.895, HL 0.875-0.957, SL 0.851-0.918, EL 0.243-0.274, ML 1.287-1.391, CI 93-96, SI 96-99.

Palp formula 3,2; mandible generally with 6 teeth, apical largest, subapical next largest, 4 basal smallest and subequal in size (basal teeth vary from 4-6, and right and left mandible of same individual can vary in basal tooth number); dorsal surface of mandible coarsely striate; clypeus bulging; compound eye set in slight concavity of head capsule, most evident posterior to eye, ventral margin of concavity delimited by small carina (concavity and ventral carina of variable strength); occipital carina thin and not visible in full-face view; face and clypeus largely smooth and shining, with about 10 longitudinal linear carinulae on clypeus, coarse carinulae on malar space between compound eye and mandible, frontal carina fading into 2-3 longitudinal carinulae posteriorly, extending to about mid-length of compound eye, variable longitudinal etching elsewhere on face, 1-2 concentric carinulae around antennal fossa; ventral surface of head smooth and shining, anterior ends of occipital carina extend about $1 /$ 3 distance to hypostomal margin; mesosoma generally smooth and shiny; anepisternum, katepisternum, and lower sides of propodeum overlain with longitudinal carinulae (of variable strength on katepisternum); dorsal surface of propodeum concave; juncture of dorsal and posterior faces concave medially, forming blunt angles laterally; posterior face of propodeum with about 5 transverse carinulae; foraminal carina entire; dorsal petiole, postpetiole, 
and gaster smooth and shining, petiole and postpetiole with a few transverse posterodorsal carinulae; ventral keel of petiole in the form of a low translucent flange, forming a short angular tooth anteriorly, splitting and becoming two small subparallel carinulae posteriorly; posterolateral petiole with longitudinal carina, delimiting posteroventral concavity between lateral carina and ventral keel; ventral margin of postpetiole with short tooth; femora, tibiae, scapes, and dorsal surface of mandible covered with abundant subdecumbent setae; face, dorsal mesosoma, dorsal petiole and postpetiole with moderately abundant suberect coarse setae; dorsal gaster with dense suberect coarse setae; general body and appendage color orange, gaster darker, dorsal setae amber.

Queen. Measurements ( $\mathrm{n}=3$ ): HW 0.939-1.023, HL 0.929-0.950, SL 0.905-0.945, EL 0.336-0.341, ML 1.529-1.578, CI 101-108, SI 92-96.

Palp formula 3,2 or 4,3, with variable or partial fusion of terminal segments; general shape, sculpture, and pilosity characters, including mandibular dentition and sculpture, similar to worker; parapsidal lines barely visible; wing venation as in Fig. $7 \mathrm{H}$.

Male. Measurements (n=1): HW 0.898, HL 0.891, SL 0.759, EL 0.525, ML 1.643, CI 101, SI 85.

Palp formula 4,3; mandible with 5 distinct teeth, apical largest, diminishing in size basally; dorsal surface of mandible striate; antenna with third segment bent, creating a kink; clypeus and face with longitudinal carinulae; head capsule with concavity around compound eye, like worker; fused notaulae present anteromedially, parapsidal lines distinct; wing venation similar to queen; ventral margin of petiole a more delicate version of condition in worker and queen; abundant coarse suberect setae on dorsal head, mesosoma, and metasoma; color orange with darker gaster, lighter appendages, antennal segments $2-4$ nearly white.

Biology. Megalomyrmex adamsae is a specialized predator of Attini, like its close relative M. symmetochus. Colonies cohabit nests with their attine hosts as "agro-predators," feeding on fungal mycelia and perhaps attine brood. Megalomyrmex adamsae and M. symmetochus differ in host preference: M. adamsae is typically found in Trachymyrmex Forel nests, M. symmetochus in Sericomyrmex Mayr nests (Adams, pers. comm.).

Etymology. This species is named for Rachelle Adams, whose extensive field and laboratory work has greatly advanced our understanding of the genus Megalomyrmex.

Comments. Megalomyrmex adamsae and M. symmetochus are very similar species. There is molecular evidence that the two are probably sister taxa (Adams, pers. comm.). The characters differentiating them in the diagnosis are consistent in Central America and the concordant molecular, morphological, and behavioral characters strongly support the existence of two sympatric species in central Panama.

I examined three collections from near Manaus, Brazil, and one collection from Peru that are in the symmetochus complex but do not cleanly fall into either adamsae or symmetochus. They vary in coarseness of pilosity and are somewhat in between the states of adamsae and symmetochus, the scape is long like symmetochus, the ventral petiolar keel is more like adamsae than symmetochus, they nest with Trachymyrmex. Molecular evidence weakly alligns them with adamsae (Adams, pers. comm.).

Other South American examples of the symmetochus complex have been reported. Brown observed a colony from near Manaus, Brazil (reported as silvestrii in Kempf \& Brown 1968; reidentified as symmetochus by Brandão 1990). He reported "The colony ... was found in a small rotten $\log$ in rain forest on 26.VIII.1962, in a small chamber with a small species of Trachymyrmex. The ants of both species were found throughout the fungus garden of the chamber, but off to one side in a small chamber was found a group of the Trachymyrmex clustered with a small piece of fungus garden unoccupied by Megalomyrmex. ... the situation suggested that the M. silvestrii colony had successfully attacked and moved into the attine nest, and was in the process of plundering it." Brandão (1990) reported a collection from Belem, PA, Brazil, from a nest of an unidentified Trachymyrmex.

Additional material examined. All collections of adamsae have been from Pipeline Road in Panama, near Barro Colorado Island, all from Trachymyrmex nests, from 1999 to 2005. Additional collections are those by A. M. Green (AMG031210-02) and R. Adams (RMMA050727-06, RMMA050801-08, RMMA050818-05, RMMA990930-03, RMMA990930-19).

Collections of adamsae-like material from South America are BRASIL: Amazonia: Manaus, Headquarters of Empresa Brasileira de Pesquisa Agropecuaria (EMBRAPA)-Amazonia Occidental, located at kilometer 28 of highway AM010, 02 $52^{\prime} 48^{\prime \prime S}, 059^{\circ} 58^{\prime} 48^{\prime \prime} \mathrm{W}, 50 \mathrm{~m}$, primary rainforest, 20 Jun 2003 (C. Rabeling); Dimona, 02 20'19"S, 06006'10"W, 85 m, forest, 16 Jan 2009 (S. E. Solomon); Reserva Campina, EEST Km 44, 18 Aug 1992 (T.R. Schultz \& J. D'Arc); PERU: Manú: Huacaria, 1254'10"S, 071²5'25"W, 600 m, wet forest, 29 May 2004 (C. Rabeling). 

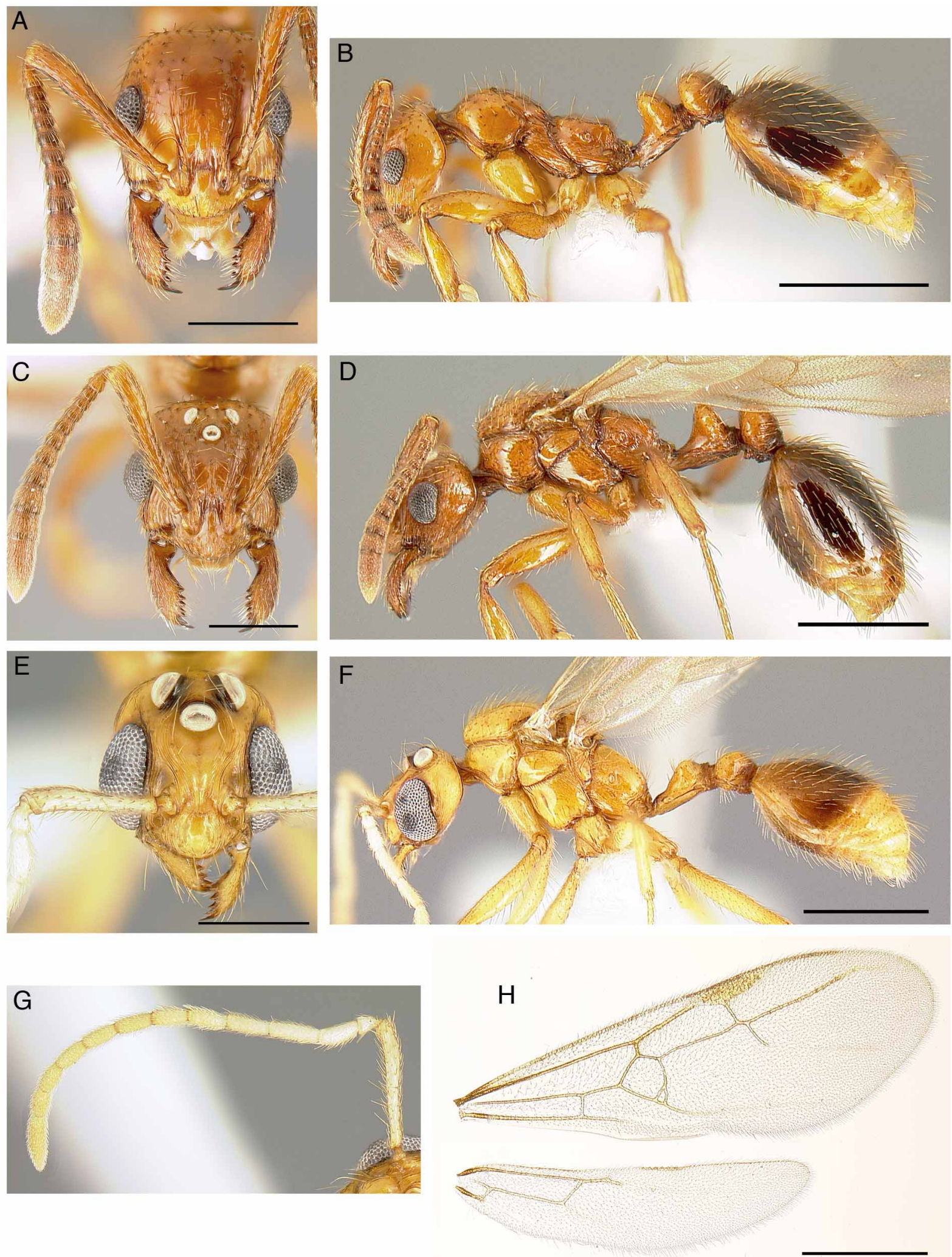

FIGURE 7. Megalomyrmex adamsae. A. Holotype worker, face view. B. Same, lateral view. C. Paratype queen, face view. D. Same, lateral view. E. Paratype male, face view. F. Same, lateral view. G. Male antenna. H. Queen fore and hindwing. Scale bars on face views $=0.5 \mathrm{~mm}$, on lateral views and wings $=1.0 \mathrm{~mm}$. 


\section{Megalomyrmex drifti Kempf}

(Figs 1C, 4B)

Megalomyrmex drifti Kempf, 1961: 504, figs 9-11. Holotype worker, paratype workers, queen: Dirkshoop, Surinam [MZSP] (not examined). Brandão, 1990: 448, description of male. See also: Kempf, 1970: 362.

Measurements. Worker: HW 0.40-0.55, HL 0.53-0.65, SL 0.40-0.55, ML 0.65-0.80 (n=20, from Brandão, 1990). Geographic range. Widespread in tropical South America, north through Central America to southern Mexico.

Biology. This species occurs in moist to wet forest habitats, in mature and second growth forest. Most collections are from below $600 \mathrm{~m}$ elevation, but collections from $1500 \mathrm{~m}$ cloud forest are known. Workers and occasionally queens are moderately abundant in Winkler samples of sifted litter. In Costa Rican wet forest I found a nest in a dead stick in the leaf litter; it contained abundant workers, brood, alate queens, and males. The collection was made on 9 November 2002, the height of the wet season.

Comments. Specimens I have examined from Costa Rica have a pair of carinae on the worker and queen clypeus, a character used as part of the species diagnosis by Kempf (1961). However, specimens from Honduras to Mexico lack the clypeal carinae. They are very similar in most other respects, and I consider this geographic variation within a single species.

Material examined. COSTA RICA: Guanacaste: Bosque Humedo, Santa Rosa Nat. Park, $10^{\circ} 51^{\prime} \mathrm{N}, 085^{\circ} 37^{\prime} \mathrm{W}$, 300 m, 12 Jul 1985 (J. Longino); Heredia: 7 km SW Pto. Viejo, 10²4'14"N, 08402'22"W, 160 m, mature wet forest, 19 Apr 2007 (Gilberth H / Felix C); 16 km SSW Pto. Viejo, 10¹9'03"N, 08402'56"W, 500 m, 11 Jul 2006

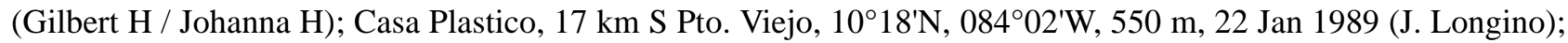

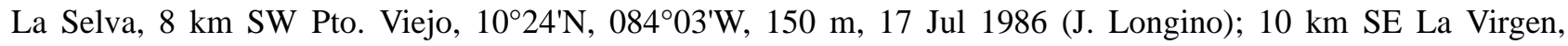
$10^{\circ} 20^{\prime} \mathrm{N}, 084^{\circ} 05^{\prime} \mathrm{W}, 500 \mathrm{~m}$, wet forest, 9 Nov 2002 (J. Longino); $11 \mathrm{~km}$ ESE La Virgen, $10^{\circ} 21^{\prime} \mathrm{N}, 084^{\circ} 03^{\prime} \mathrm{W}, 300$

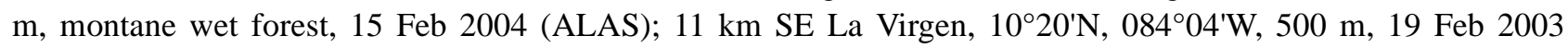
(ALAS); Limón: Hitoy Cerere Biol. Reserve, $09^{\circ} 40^{\prime} \mathrm{N}, 083^{\circ} 02^{\prime} \mathrm{W}, 100 \mathrm{~m}$, mature and second growth wet forest, 1 Sep 1985 (J. Longino); Puntarenas: Sirena, Corcovado National Park, 08²9'N, 083³6'W, 5 m, 18 Dec 1990 (J.

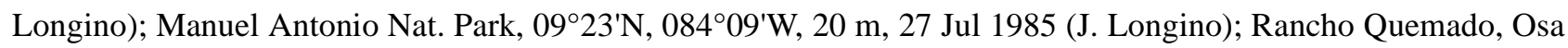
Peninsula, 08² $42^{\prime} \mathrm{N}, 083^{\circ} 33^{\prime} \mathrm{W}, 200 \mathrm{~m}, 15$ Dec 1990 (J. Longino); $13 \mathrm{~km}$ SSW Pto. Jimenez, 08²4'24"N, 083¹9'42"W, $130 \mathrm{~m}$, tropical rainforest, 10 Mar 2008 (J. Longino); GUATEMALA: El Progreso: $3.7 \mathrm{~km} \mathrm{SW}$ Morazán, $14^{\circ} 54^{\prime} 18^{\prime \prime N}, 090^{\circ} 09^{\prime} 13^{\prime \prime W}, 460$ m, tropical dry forest, 8 Jul 2007 (M. Branstetter); $12 \mathrm{~km}$ N San Agustin Acasaguastlan, $15^{\circ} 02^{\prime} 30^{\prime \prime} \mathrm{N}, 089^{\circ} 58^{\prime} 00^{\prime \prime} \mathrm{W}, 1200 \mathrm{~m}$, oak pine forest, $3 \mathrm{Jun} 1991$ (R. S. Anderson); Izabal: $5 \mathrm{~km}$ NW Morales, $15^{\circ} 30^{\prime} 50^{\prime \prime} \mathrm{N}, 088^{\circ} 51^{\prime} 56^{\prime \prime} \mathrm{W}, 250 \mathrm{~m}, 2^{\circ}$ lowland tropical rainforest, 17 May 2009 (LLAMA); $16 \mathrm{~km}$ ESE Morales, $15^{\circ} 24^{\prime} 46^{\prime \prime} \mathrm{N}, 088^{\circ} 42^{\prime} 37^{\prime \prime} \mathrm{W}, 415$ m, 19 May 2009 (LLAMA); Petén: Cerro Cahuí, 1700'09"N,

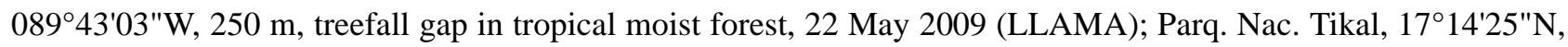
089 37'19"W, 270 m (LLAMA); 13 km NW Machaquilá, 16²6'44"N, 089³3'00"W, 400 m, 27 May 2009

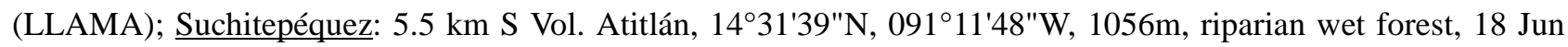
2009 (R. S. Anderson); HONDURAS: Olancho: 14 km WSW Catacamas, 1447'59"N, 086 00'51"W, $600 \mathrm{~m}$, tropical moist forest, 13 May 2009 (J. Longino); MEXICO: Chiapas: Nahá, 1658'27"N, 091³5'09"W, 950 m, montane wet forest, $14 \mathrm{Jul} 2007$ (J. Longino); $2.5 \mathrm{~km}$ S Nuevo San Juan Chamula, 1607'25"N, 091 ${ }^{\circ} 26^{\prime} 44^{\prime \prime} \mathrm{W}, 750$ $\mathrm{m}$, montane evergreen forest (roadside), $22 \mathrm{Jul} 2007$ (R. S. Anderson); $6 \mathrm{~km} \mathrm{SW}$ Ocosingo, 16 $52^{\circ} 02^{\prime \prime} \mathrm{N}$, 092 04'43"W, $1400 \mathrm{~m}$, wet oak pine forest, 16 Sep 1992 (R. S. Anderson); 8 km SE Salto de Agua, 17³0'56"N,

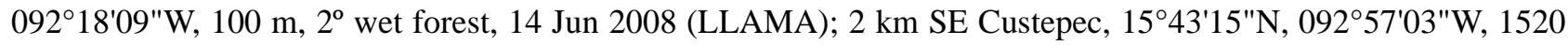
$\mathrm{m}$, mesophil forest, 17 May 2008 (LLAMA); Playón de la Gloria, 1608'12"N, 09055'00"W, $155 \mathrm{~m}$, lowland wet

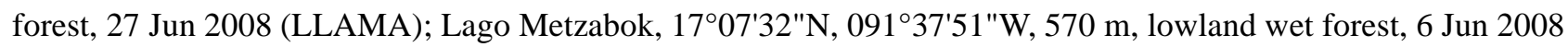
(LLAMA).

\section{Megalomyrmex foreli Emery}

(Figs 1A, 2B)

Megalomyrmex foreli Emery, 1890: 46, pl. 5, fig. 3. Lectotype worker (designated by Brandão 1990: 434): Jimenez [near Guapiles, Prov. Limón], Costa Rica [MCSN] (examined). Forel, 1899: 58, description of male. See also: Brandão, 1990: 434; 2003: 152. 
Megalomyrmex latreillei Emery, 1890: 47 (footnote), pl. 5, fig. 4. Holotype worker: Cumbase [probably San Antonio de Cumbasa, San Martin], Peru [MCSN] (not examined). Brandão, 1990: 436, description of male. Synonymy by Brandão, 2003: 152.

Measurements. Worker: HW 1.50-1.86, HL 1.80-2.13, SL 1.98-2.58, ML 2.28-3.09 (n=43, from Brandão, 1990).

Geographic range. Costa Rica south to Andean regions of Colombia, Ecuador, and northern Peru.

Biology. This species occurs in moist to wet forest habitats, in mature and second growth forest. It typically occurs in mountainous regions; in Costa Rica collections are from 100-1200 m elevation. Workers are large, conspicuous ants that may be found foraging on the ground or on low vegetation. They are attracted to extrafloral nectaries and will tend Hemiptera for honeydew.

In Central America, M. foreli is known from Costa Rica, where it is not common. I have collected foreli in the central cordilleras and on the Osa Peninsula. Workers can be found on the ground and low vegetation as diurnal or nocturnal foragers. Males come to lights. On the Osa, I encountered them in the hilly interior areas, and not in coastal areas. Workers can accumulate on sources of extrafloral nectar; I once observed 15 workers together on one Costus inflorescence.

I observed a colony at the El Ceibo site on the Barva Transect in Braulio Carrillo National Park. It was in the understory of mature wet forest at night. I saw active workers on a large liana stem and discovered that there were cavities in the stem. I saw two entrance holes in the liana, with workers visible inside, and another entrance hole in the ground at the side of the liana. The workers were aggressive, readily attacking my fingers when disturbed. One of the upper entrance holes was concealed by a small aroid with basket roots. There was carton construction around the aroid roots, possibly made by the Megalomyrmex. The aroid also covered two large Margarodidae being tended by workers. Penny Gullan identified them as immature females of the subfamily Monophlebinae, probably tribe Llaveiini.

Specimens from Colombia bear labels "Cacao - associated with membracids Horiola picta (Coquebert)," and "arboles de cacao" (reported in Brandão 1990). Jones et al. (1999) studied the venom alkaloids of M. foreli (= M. latreillei) workers collected in Ecuador.

Comments. Material I have examined from Costa Rica varies geographically in degree of development of propodeal tubercles and color. A specimen from Limón province is strongly tuberculate and red brown. Specimens from the San Vito area vary from strongly to weakly tuberculate and are orange brown. Specimens from the Osa Peninsula are not at all tuberculate and are red brown with strongly contrasting darker gaster. Specimens from the Osa also have the head narrower and the occipital carina more visible in face view. In contrast, specimens from the central ranges have a broader head with the occipital carina not or barely visible in face view.

Additional material examined. COSTA RICA: Alajuela: Laguna Poco Sol, $10^{\circ} 21^{\prime} \mathrm{N}, 084^{\circ} 40^{\prime} \mathrm{W}, 800 \mathrm{~m}$, second growth wet forest, 10 Mar 2006 (J. Longino); Guanacaste: $9 \mathrm{~km} \mathrm{NE} \mathrm{Sta.} \mathrm{Elena,} 10^{\circ} 23^{\prime} \mathrm{N}, 084^{\circ} 47^{\prime} \mathrm{W}, 650 \mathrm{~m}$, moist forest, river edge, 2 Mar 1998 (J. Longino); Heredia: $10 \mathrm{~km} \mathrm{SE} \mathrm{La} \mathrm{Virgen,} 10^{\circ} 20^{\prime} \mathrm{N}, 084^{\circ} 05^{\prime} \mathrm{W}, 500 \mathrm{~m}$, wet forest, 10 Nov 2002 (J. Longino); $11 \mathrm{~km} \mathrm{SE} \mathrm{La} \mathrm{Virgen,} 10^{\circ} 20^{\prime} \mathrm{N}, 084^{\circ} 04^{\prime} \mathrm{W}, 500 \mathrm{~m}$, montane wet forest, $21 \mathrm{Mar}$

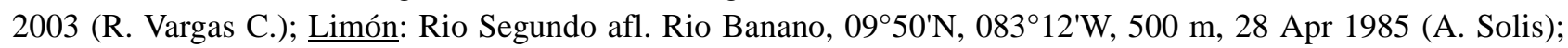

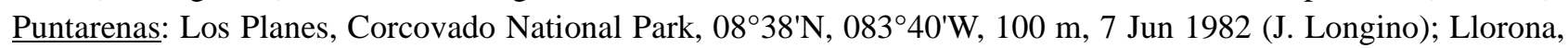
Corcovado National Park, $08^{\circ} 35^{\prime} \mathrm{N}, 083^{\circ} 42^{\prime} \mathrm{W}, 5 \mathrm{~m}, 5$ Dec 1981 (J. Longino); Rio Nino, Corcovado National Park, $08^{\circ} 33^{\prime} \mathrm{N}, 083^{\circ} 29^{\prime} \mathrm{W}, 300 \mathrm{~m}, 26 \mathrm{Feb} 1981$ (J. Longino); Cerro Rincon, Corcovado National Park, 08³3'N,

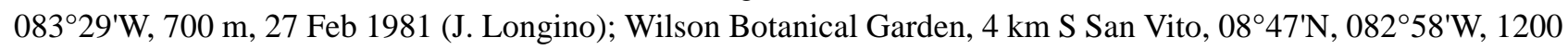
m, 28 Feb 1989 (J. Longino).

\section{Megalomyrmex incisus Smith}

(Figs 1D, 4A)

Megalomyrmex incisus Smith, M.R. 1947: 102. Holotype worker: Barro Colorado Island, Panama, Jul-Oct 1943 (Zetek) [USNM] (not examined). Brandão, 1990: 451, description of male. Brandão, 2003: 157, description of queen.

Measurements. Worker: HW 0.65-0.87, HL 0.63-0.86, SL 0.63-0.78, ML 0.98-1.18 ( $\mathrm{n}=20$, from Brandão, 1990).

Geographic range. Southern Mexico south to central Brazil and Peru, absent in Costa Rica.

Biology. This species occurs in moist to wet forest habitats, from sea level to $1000 \mathrm{~m}$ elevation. It is most often 
encountered as workers in Winkler samples of sifted leaf litter. Colonies have twice been collected from dead wood on the forest floor (Brandão, 2003).

Comments. Material from Central America and Venezuela is very similar in color and mandibular dentition. Workers are solid black, and the basal teeth of the mandible vary in size, the second from the base being much larger than the flanking teeth. As a result the mandible appears falcate rather than triangular. A collection from Colombia is distinctive, with the color lighter red brown and the basal teeth of the mandible of more uniform size. Other size and shape characters, including the highly distinctive petiole, are the same as other M. incisus. M. incisus has a range disjunction. It is moderately abundant in Winkler samples from Guatemala and southern Mexico, occurs in Panama and Venezuela, yet has never been collected in Costa Rica, in spite of extensive survey work there.

Material examined. BRAZIL: Amazonas: Manaus, $03^{\circ} 07^{\prime} \mathrm{S}, 060^{\circ} 02^{\prime} \mathrm{W}, 3$ Nov 1993 (A. B. Casimiro); COLOMBIA: Leticia: El Zafie, $04^{\circ} 13^{\prime} \mathrm{S}, 069^{\circ} 56^{\prime} \mathrm{W}, 150 \mathrm{~m}, 2-4$ Oct 2007 (L. E. Franco \& S. Florica); GUATEMALA: Izabal: $5 \mathrm{~km}$ NW Morales, $15^{\circ} 30^{\prime} 38^{\prime \prime N}, 088^{\circ} 51^{\prime} 39^{\prime \prime} \mathrm{W}, 195 \mathrm{~m}, 2^{\circ}$ lowland tropical rainforest, 17

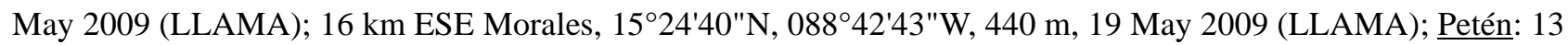
km NW Machaquilá, 16² $26^{\prime} 44^{\prime \prime} \mathrm{N}, 089^{\circ} 33^{\prime} 00^{\prime \prime} \mathrm{W}, 400 \mathrm{~m}$, tropical moist forest, 27 May 2009 (LLAMA); MEXICO:

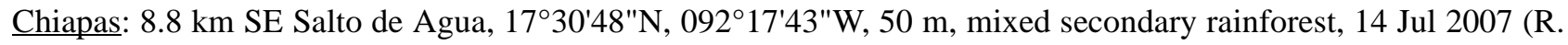
S. Anderson); Playón de la Gloria, $16^{\circ} 08^{\prime} 52^{\prime \prime} \mathrm{N}, 090^{\circ} 53^{\prime} 48^{\prime \prime} \mathrm{W}, 170 \mathrm{~m}, 24$ Jun 2008 (LLAMA); Lago Metzabok, $1^{\circ} 07^{\prime} 32^{\prime \prime} \mathrm{N}, 091^{\circ} 37^{\prime} 51^{\prime \prime} \mathrm{W}, 570 \mathrm{~m}$, lowland wet forest, 6 Jun 2008 (LLAMA); Nahá, 1658'49"N, 091³5'10"W, $860 \mathrm{~m}, 2^{\circ}$ mesophil forest, 12 Jun 2008 (M. Branstetter); PANAMA: Canal Zone: Barro Colorado Island, 09 $09^{\prime} \mathrm{N}$, 07951'W, 100 m, 2 Jul 1979 (W. L. Brown); PERU: Pasco: nr. Pozuzo, 1000 m, steep primary forest above farms,

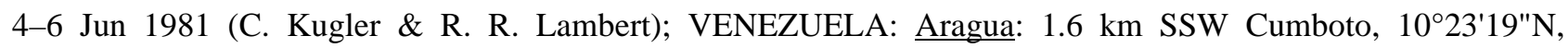
$067^{\circ} 47^{\prime} 52 " \mathrm{~W}, 150 \mathrm{~m}$, riparian dry forest, 15 Aug 2008 (J. Longino).

\section{Megalomyrmex miri Brandão}

Megalomyrmex miri Brandão, 1990: 452, figs 117, 118. Holotype worker: Zent, Limón Prov., Costa Rica, Mar. 1924 (Mann) [USNM] (not examined).

Measurements. Worker: HW 0.48, HL 0.50-0.55, SL 0.48-0.50, ML 0.75-0.78 (n=2, from Brandão, 1990).

Geographic range. Costa Rica.

Comments. This species is known only from the type specimens and has no biological data. It is extremely similar to M. wettereri in color, size, shape, measurements, and pilosity. It differs in having a complete foraminal carina and some transverse rugosities on the anteroventral petiolar process.

\section{Megalomyrmex modestus Emery}

Megalomyrmex modestus Emery, 1896: 94. Lectotype worker (designated by Brandão 1990: 425): Suerre [near Jimenez, Limón Prov.], Costa Rica [MCSN] (examined). Brandão, 1990: 426: description of queen, male.

Measurements. Worker: HW 0.81-0.93, HL 1.00-1.12, SL 1.02-1.12, ML 1.29-1.45 (n=13, from Brandão, 1990). Geographic range. Costa Rica, Panama, Colombia, Venezuela.

Biology. Forel (1899) reported that the type specimens were collected by A. Alfaro from a rotten log. Kugler collected specimens in Colombia, from a "large nest in rotten log, soil - rocks, under forest" (reported in Brandão 1990).

In Costa Rica, M. modestus is found in mature wet forest of the Atlantic slope. Although it occurs at sea level, it is most abundant at middle elevations, $500-800 \mathrm{~m}$. Nests are subterranean and very large. From these nests, inconspicuous covered galleries extend large distances up trees and under liana stems, and workers may be found under epiphyte mats in the canopy. Workers tend Coccoidea under the shelters. Workers are occasionally collected at baits on the forest floor, but in general they are not often seen as exposed foragers.

At Refugio Eladio, on the Río Peñas Blancas, I found a nest on the bank of a small stream. An area of excavated soil about $2 \mathrm{~m}$ across covered the ground. There were hundreds of small entrances, and excavations in the 
surface soil turned up only scattered workers, and no brood. As I dug deeper into the center of the nest (more than $20 \mathrm{~cm}$ deep) workers became more dense and I began finding adult males and some brood. At a depth of about arm's length workers were very dense, brood more abundant, and two dealate queens were turned up. The soil was very friable, and I could not discern any gallery or chamber structure. Given that I was digging in only a small part of the colony, and turned up two queens, the colony must have had many queens. Around the periphery of the colony there were abundant Coccoidea (Pseudococcidae?) in the soil.

Additional material examined. COSTA RICA: Alajuela: Casa Eladio, Rio Penas Blancas, $10^{\circ} 19^{\prime} \mathrm{N}$,

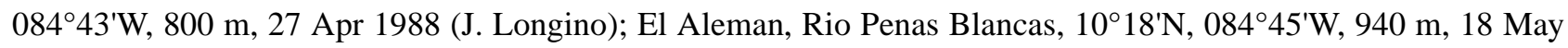

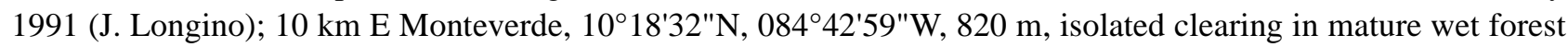
area, open lawn area at edge of building, 3 Mar 2010 (J. Longino); Cartago: $5 \mathrm{~km}$ E Turrialba, $09^{\circ} 54^{\prime} \mathrm{N}, 083^{\circ} 38^{\prime} \mathrm{W}$, 945 m; Heredia: La Selva Biological Station, 10²4'59"N, 08401'12"W, 50 m, 26 Jan 2004 (M Molina, H Garcia); 7 km SW Pto. Viejo, 10²4'14"N, 08402'22"W, 160 m, 3 Mar 2005 (M Molina/ G Hurtado); 16 km SSW Pto. Viejo, 10 $19^{\prime} 03^{\prime \prime N}, 084^{\circ} 02^{\prime} 56^{\prime \prime W}, 500$ m, 17 Oct 2005 (Marcos M/ Deimer A/ Gilberth H/ Felix C/ Joel A); Cantarrana, $11 \mathrm{~km}$ ESE La Virgen, 10²0'43"N, 08403'28"W, 300 m, 20 Mar 2006 (Marcos M, Gilberth H, Felix

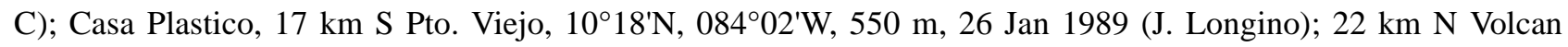
Barba, $10^{\circ} 20^{\prime} \mathrm{N}, 084^{\circ} 04^{\prime} \mathrm{W}, 500 \mathrm{~m}, 7 \mathrm{Mar} 1985$ (J. Longino); Rara Avis, $17 \mathrm{~km}$ S Pto. Viejo, $10^{\circ} 18^{\prime} \mathrm{N}, 084^{\circ} 03^{\prime} \mathrm{W}$, 700 m, 11 Sep 1985 (J. Longino); 17 km N Vol. Barba, 10²17'N, 08405'W, 880 m, 14 Jul 1986 (J. Longino); 11 km ESE La Virgen, $10^{\circ} 21^{\prime} 00^{\prime \prime} \mathrm{N}, 084^{\circ} 03^{\prime} 00^{\prime \prime} \mathrm{W}, 300 \mathrm{~m}$, wet forest, $15 \mathrm{Feb} 2004$ (ALAS); $11 \mathrm{~km}$ SE La Virgen, $10^{\circ} 20^{\prime} \mathrm{N}$,

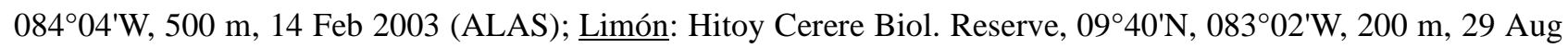
1985 (J. Longino); Rio Toro Amarillo, vic. Guapiles, $10^{\circ} 13^{\prime} \mathrm{N}, 083^{\circ} 48^{\prime} \mathrm{W}$.

\section{Megalomyrmex mondabora Brandão}

(Figs 6A, 8A-H)

Megalomyrmex mondabora Brandão, 1990: 442, figs 95, 96. Holotype worker: Costa Rica, Cartago, Turrialba, 18-22 Jan 1973 (W. L. Brown Jr.) [MCZC] (examined).

Measurements (holotype): HW 0.742, HL 0.875, SL 1.078, EL 0.229, ML 1.34, SI 123, CI 85.

Measurements $(\mathrm{n}=10)$ : HW 0.742-0.878, HL 0.874-0.963, SL 1.078-1.210, EL 0.299-0.302, ML $1.325-1.497$, CI 85-92, SI 121-128.

Geographic range. Costa Rica.

Description. Queen (previously undescribed). Measurements (n=3): HW 0.939-0.972, HL 0.992-1.012, SL 1.146-1.172, EL 0.327-0.333, ML 1.602-1.645, CI 95-96, SI 114-118.

Palp formula 3,2; general shape, sculpture, and pilosity characters, including mandibular dentition and sculpture, similar to worker; parapsidal lines present, extending from posterior border of mesoscutum to midlength; wing venation as in Fig. $8 \mathrm{H}$.

Male (previously undescribed). Measurements (n=2): HW 0.813-0.923, HL 0.750-0.836, SL 0.344-0.401, EL 0.364-0.411, ML 1.378-1.553, CI 45, SI 46-48.

Palp formula 4,3; mandible with large apical tooth, more than twice length of subapical tooth, subapical tooth followed by 5 small basal teeth of somewhat irregular size and spacing; antenna with fourth segment bent, with a sharp kink at 3/4ths length, 5th and 6th segments weakly bent, remaining segments straight; occipital carina welldeveloped as a distinct flange, but not visible in full-face view; fused notaulae present anteromedially, parapsidal lines distinct; wing venation similar to queen; ventral margin of petiole a more delicate version of condition in worker and queen; abundant flexuous suberect setae on dorsal head, mesosoma, and metasoma; color dark red brown to black, appendages lighter amber, antennal segments 2, 3, and base of 4 nearly white; wings pale amber, nearly white.

Biology. In Costa Rica this species occurs in wet forest habitats, typically in mature rainforest. Collections are from sea level to $800 \mathrm{~m}$ elevation on the Atlantic slope of the Cordillera Volcanica Central, Cordillera de Talamanca, and Cordillera de Guanacaste. It is a specialized nest parasite of attines and is found most often in nests of Cyphomyrmex cornutus Kempf (Adams \& Longino 2007). It cohabits with C. cornutus in their nests, feeding on both host brood and the host's fungal symbiont.

Comments. See further discussion under M. mondaboroides. 

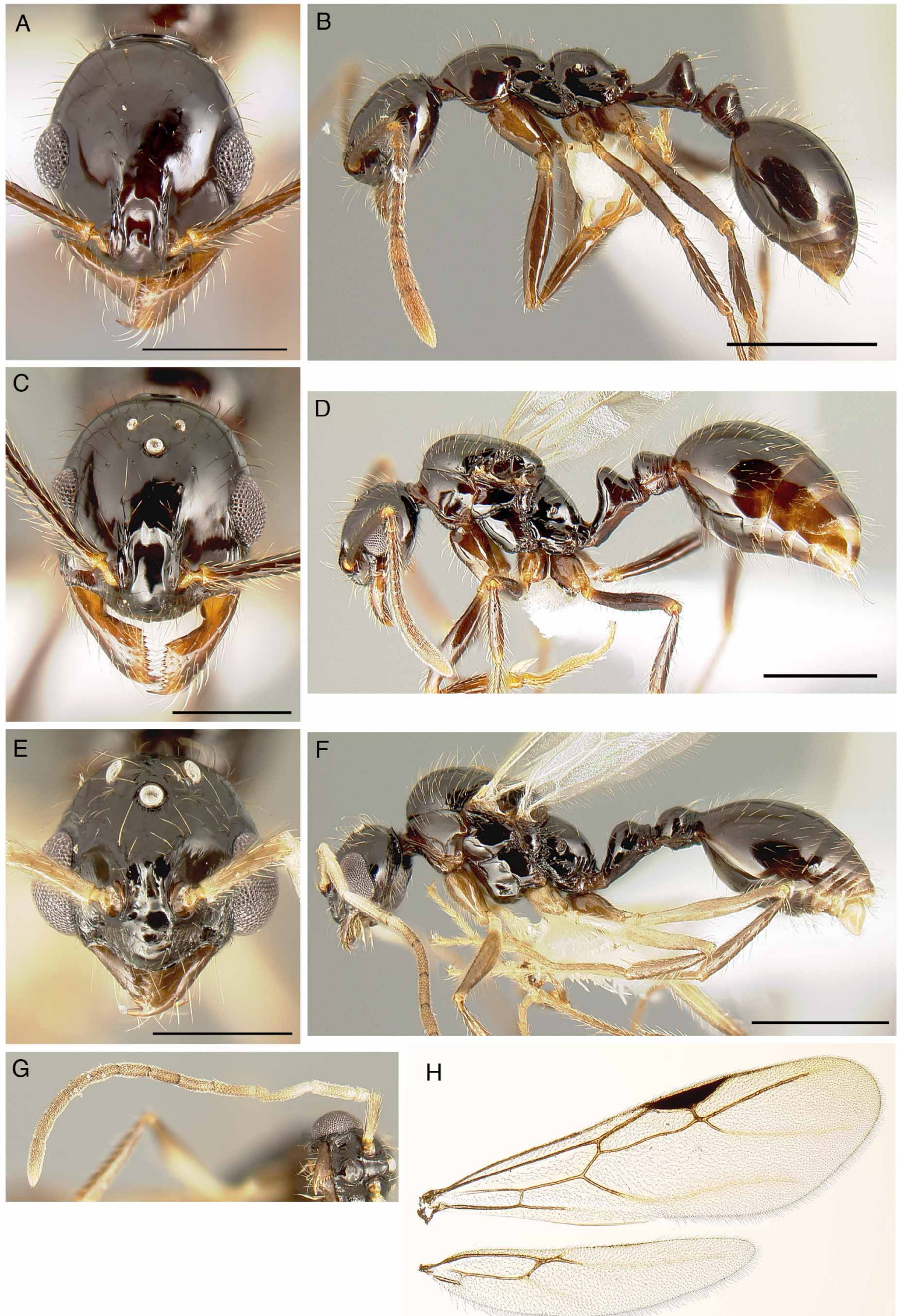

FIGURE 8. Megalomyrmex mondabora. A. Worker (INBIOCRI001280853), face view. B. Same, lateral view. C. Queen (CASENT0613271), face view. D. Same, lateral view. E. Male (JTLC000001520), face view. F. Same, lateral view. G. Male antenna. $\mathrm{H}$. Queen fore and hindwing. Scale bars on face views $=0.5 \mathrm{~mm}$, on lateral views and wings $=1.0 \mathrm{~mm}$. 
Additional material examined. COSTA RICA: Alajuela: Casa Eladio, Rio Penas Blancas, $10^{\circ} 19^{\prime} \mathrm{N}$,

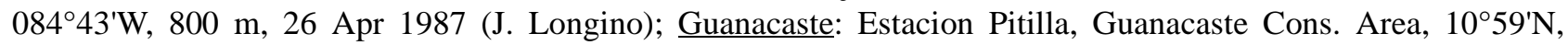
085 26'W, 700 m, wet forest, 11 Feb 1995 (J. Longino); Heredia: Cantarrana, 11 km ESE La Virgen, 10²0'43"N, 084 03'28"W, 300 m, mature wet forest, 21 Mar 2006 (Marcos M, Gilberth H, Felix C); 22 km N Volcan Barba,

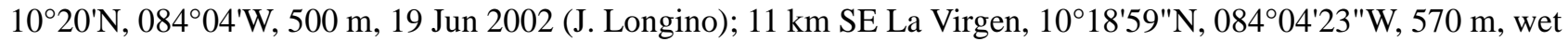
forest, 11-24 Feb 2003 (A. G. Himler).

\section{Megalomyrmex mondaboroides Longino, new species}

(Figs 1E, 5B, 5D, 6B, 9A-H)

Megalomyrmex mondabora Brandão (part): Adams \& Longino, 2007:136-143.

Type material. Holotype worker. PANAMA, Panama: El Llano, 9.27956 ${ }^{\circ} \mathrm{N} 78.96150^{\circ} \mathrm{W}, 300 \mathrm{~m}, 30 \mathrm{Mar} 2001$ (H. Fernandez-Marin\#HF010330-50) [MCZ, unique specimen identifier JTLC000015325]. Paratypes: Same data as holotype, 1 queen, 1 male [MCZ, CASENT0613246, CASENT0613247], 1 worker [MZSP, CASENT0613228], 1 queen, 1 male, 1 worker [CAS, CASENT0613229], 2 workers [USNM, USNMENT693033, USNMENT693032], 1 worker [LACM, JTLC000015326]; discrepancy in paratype CASENT0613230; same data as holotype except (C. Currie\#CC010324-50), 2 workers [USNM, CASENT0613226, CASENT0613227].

Geographic range. Panama, Costa Rica.

Diagnosis. Worker differing from M. mondabora as follows: (1) scape shorter, SI < 114; (2) frontal carinae relatively smaller and less elevated; (3) occipital carina thinner, less pronounced; (4) propodeum less convex, medial portion above petiolar insertion usually flat to slightly concave; (5) color black to lighter red brown (always dark red brown to black in mondabora). Queen differing as follows: (1) scape shorter, SI < 105 vs. > 113; (2) frontal carinae relatively smaller and less elevated; (3) occipital carina thinner, less pronounced. Male differing as follows: (1) size smaller, HW $<0.8 v s$. $>0.8$; (2) frontal carinae relatively smaller and less elevated; (3) occipital carina thinner, less pronounced; (4) antennae completely white (segments 7 and above more strongly infuscated in mondabora).

Description. Worker. Measurements (holotype): HW 0.718, HL 0.783, SL 0.851, EL 0.231, ML 1.180, CI 92, SI 109.

Measurements (n=6): HW 0.605-0.721, HL 0.642-0.788, SL 0.682-0.866, EL 0.188-0.261, ML 0.893-1.180, CI 91-94, SI 106-110.

Palp formula 4,3; mandible with large apical and subapical teeth, 8-10 smaller basal teeth; most basal tooth smaller than adjacent distal tooth, so that juncture of basal and masticatory margin of mandible is rounded; dorsal surface of mandible smooth and shiny; occipital carina narrow, not visible in full-face view, anterior ends extending a short distance onto ventral surface of head, not much beyond level of foramen; face, clypeus, and ventral surface of head smooth and shiny, with a few irregular rugulae on clypeus; mesosoma largely smooth and shiny, with variable development of coarse longitudinal carinae on posterior katepisternum and metanotal groove; foraminal carina an entire semicircle delimiting propodeal foramen, some specimens with a second concentric carina above foraminal carina; petiole and postpetiole smooth and shining, posterior peduncles of both with a few concentric carinulae dorsally; ventral margin of petiole flat, with a very small anterior tooth and almost no development of a ventral keel; ventral margin of postpetiole flat; gaster smooth and shining; all dorsal body surfaces and appendages with abundant flexuous setae; color red brown, with appendages and mandibles lighter brown to a variable degree.

Queen. Measurements (n=1): HW 0.813, HL 0.847, SL 0.874, EL 0.317, ML 1.286, CI 96, SI 103.

Palp formula 4,3 or 3,2; general shape, sculpture, and pilosity characters, including mandibular dentition and sculpture, similar to worker; parapsidal lines present, extending from posterior border of mesoscutum to midlength; wing venation as in Fig. $9 \mathrm{H}$.

Male. Measurements $(\mathrm{n}=2)$ : HW 0.723-0.749, HL 0.639-0.658, SL 0.291-0.334, EL 0.350-0.355, ML 1.157-1.167, CI 113-114, SI 46-51.

Palp formula 4,3 or 3,3; mandible with large apical tooth, more than twice length of subapical tooth, subapical tooth followed by 5 small basal teeth of somewhat irregular size and spacing; antenna with kinks in basal segments, strongly flexed between 3rd and 4th segment, 4th segment bent at 3/4ths length, 5th segment bent at midlength, 6th 

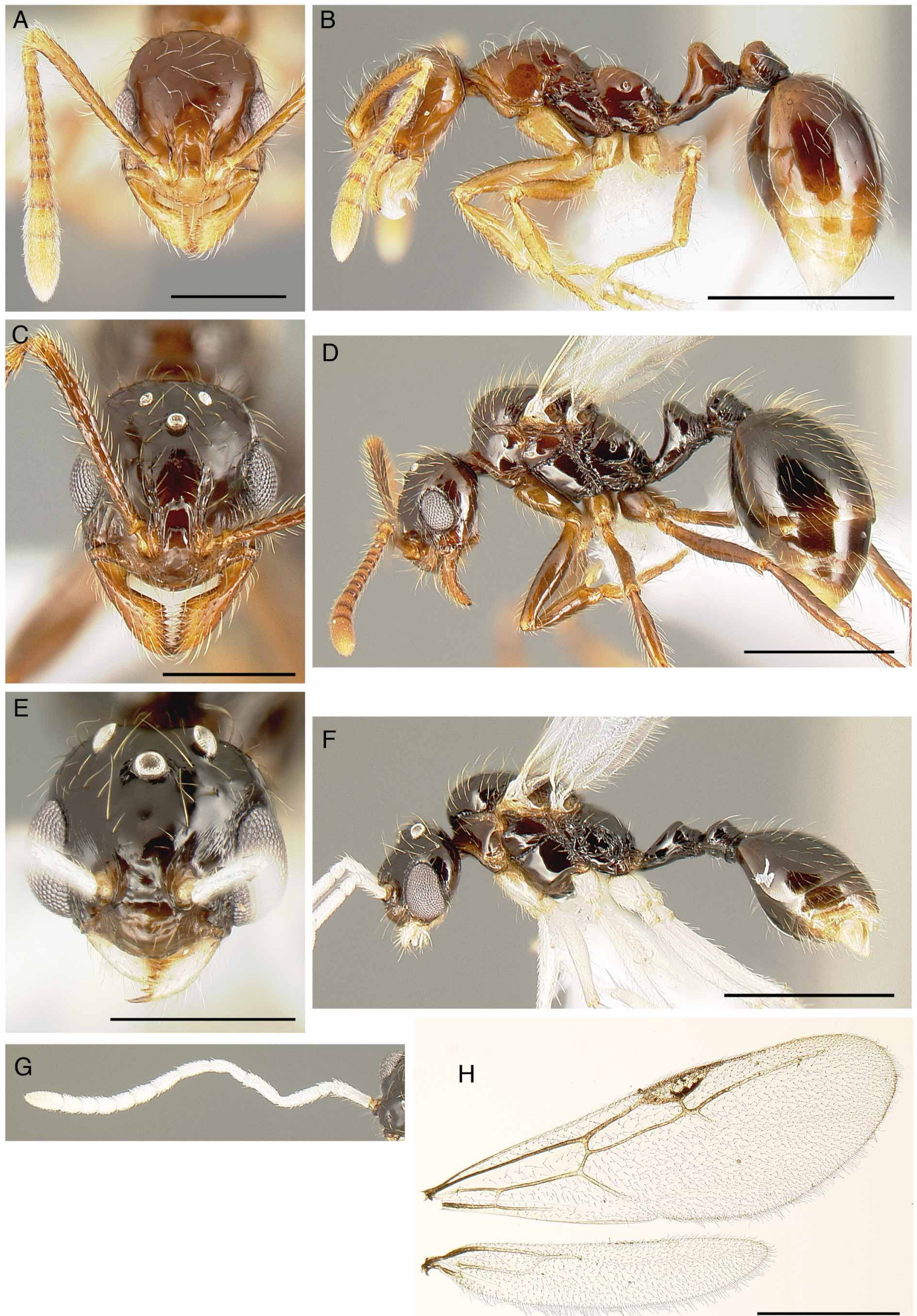

FIGURE 9. Megalomyrmex mondaboroides. A. Holotype worker, face view. B. Same, lateral view. C. Paratype queen, face view. D. Same, lateral view. E. Paratype male, face view. F. Same, lateral view. G. Male antenna. H. Queen fore and hindwing. Scale bars on face views $=0.5 \mathrm{~mm}$, on lateral views and wings $=1.0 \mathrm{~mm}$. 
segment bent near base, remaining segments straight; occipital carina very thin, not developed as a distinct flange; fused notaulae present anteromedially, parapsidal lines distinct; wing venation similar to queen but more feeble; ventral margin of petiole a more delicate version of condition in worker and queen; abundant flexuous suberect setae on dorsal head, mesosoma, and metasoma; color dark red brown to black with wings, legs (including coxae), entire antenna (including apex), and mandible contrasting ivory, nearly white.

Biology. Megalomyrmex mondaboroides occurs in lowland wet forest habitats in Panama and Costa Rica. Colonies have been collected in the nests of small attines, primarily Cyphomyrmex costatus Mann and Apterostigma goniodes Lattke. In Costa Rica a worker was collected in a Winkler sample of sifted leaf litter.

Etymology. The name of this species refers to its similarity to M. mondabora.

Comments. Megalomyrmex mondaboroides and M. mondabora are very similar species, and they were treated as a single variable species in Adams and Longino (2007). There is now evidence that the two forms are sympatric in Costa Rica, and molecular evidence suggests that the two are probably sister taxa (Adams, pers. comm.). There are also hints that both may further resolve into multiple cryptic species. Collections from Panama include two nests found with Cyphomyrmex costatus and two nests found with Apterostigma gonioides. The workers with $C$. costatus are relatively small, with $\mathrm{HL}<0.70 \mathrm{~mm}$, while the workers from A. gonioides are larger, with $\mathrm{HL}>0.78$ $\mathrm{mm}$. An isolated worker from Costa Rica is also larger, with HL about 0.78. In the case of M. mondabora, there are contrasting forms of mandibular dentition (described in the key to species). Numerous collections of a form with a large basal denticle on the mandible have been made from nests of $C$. cornutus, and this form was the subject of the behavioral study of Adams and Longino (2007). In contrast, the holotype of M. mondabora has the small basal denticle and rounded junction of $M$. mondaboroides. The holotype also differs in host association; it was accompanied by fieldnotes indicating it was associated with an Apterostigma Mayr nest. The types were collected by the renowned myrmecologist W. L. Brown, Jr., and it is inconceivable that he could have misidentified the genus (i.e., misidentifying C. cornutus). Thus in both M. mondaboroides and M. mondabora there is the potential for further division, perhaps paralleling specialization on various attine hosts. Further host-associated collections of these elusive ants are needed.

In South America, scattered collections of M. mondabora-like ants are known from Ecuador, Peru, and Amazonian Brazil. Many were collected with attine hosts. Morphologically they blur the distinctions that separate the sympatric $M$. mondaboroides and M. mondabora in Costa Rica. One can anticipate a considerably more complex story when the group is better collected throughout the range.

Additional material examined. COSTA RICA: Heredia: La Selva Biological Station, $10^{\circ} 24^{\prime} 59^{\prime \prime} \mathrm{N}$, 084 $01^{\prime} 12^{\prime \prime W}, 50$ m, mature wet forest, 14 Jun 2004 (M Molina, D Alvarez, G Hurtado); PANAMA: Pipeline Road

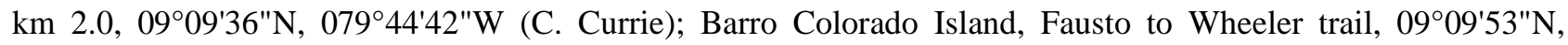
07950'12"W, 23 Dec 2004 (R. Adams); Gamboa, Pipeline Rd, 2.5 km past Rio Frijoles, 72m, 6-8 Jun 2002 (C. J. Marshall).

South American material in the mondabora complex: BRAZIL: Rondonia: Vilhena, $12^{\circ} 43^{\prime} \mathrm{S}, 060^{\circ} 07^{\prime} \mathrm{W}$, Nov

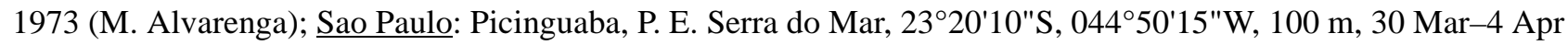
2001 (C. R. F. Brandão); ECUADOR: Napo: Tiputini, Matapalo Trail, 00³8'18"S, 07608'58"W, 14 Jun 2003 (C. Currie); Pichincha: Unión del Toachi Station, 4 km SE of station, 00¹9'16"S, 078 56'22"W, 875 m, 15 Mar 2006 (R. Adams); PERU: Madre de Dios: Manú, Huacaria, 1254'10"S, 071²5'25"W, 600 m, 28 May 2004 (R. Adams).

\section{Megalomyrmex nocarina Longino, new species}

(Figs 5A, 5C, 10A, 10B)

Type material. Holotype worker. COSTA RICA, Heredia: Estación Biológica La Selva, $10^{\circ} 26^{\prime} \mathrm{N} 83^{\circ} 59^{\prime} \mathrm{W}, 40-125$ m, 16 Sep 2005 (Proyecto TEAM AMI-1-W-044-03) [MCZ, unique specimen identifier INB0003678142]. Paratypes: Same data as holotype, except 4 Sep 2007 (Proyecto TEAM AMI-1-W-091-04), 1 worker [CAS, INB0003695485]; 12 Jun 2006 (Proyecto TEAM AMI-1-W-080-04), 1 worker [INBC, INB0003694200]; 7 km SW Pto. Viejo, $10^{\circ} 24^{\prime} 14^{\prime \prime} \mathrm{N}, 084^{\circ} 02^{\prime} 22^{\prime \prime} \mathrm{W}, 160 \mathrm{~m}, 20$ Jan 2006 (Proyecto TEAM AMI-2-W-059-03), 1 worker [LACM, INB0003680680]; same except 24 Oct 2006 (Proyecto TEAM AMI-2-W-105-06), 1 worker [USNM, INB0003697094]; same except 23 Apr 2007 (Proyecto TEAM AMI-2-W-131-10), 2 workers [UCD, CASENT0613301; INBC, INB0003699639]; 16 km SSW Pto. Viejo, 10²19'03"N, 08402'56"W, 500 m, 16 Oct 
2006 (Proyecto TEAM AMI-3-W-100-09), 1 worker [MCZ, INB0003696577]; Cantarrana, $11 \mathrm{~km}$ ESE La Virgen, 10²0'43"N, 084 03'28"W, 300 m, 26 Feb 2007 (Proyecto TEAM AMI-4-W-123-09), 5 workers [CAS, CASENT0613296; LACM, CASENT0613297; MCZ, CASENT0613298; USNM, CASENT0613299; MZSP, CASENT0613300; INBC, INB0003646495].

Geographic range. Costa Rica.

Diagnosis. Worker differing from M. mondabora and M. mondaboroides as follows: (1) foraminal carina absent dorsally; (2) anterior clypeal margin more strongly produced and subangular, not evenly rounded.

Description. Worker. Measurements (holotype): HW 0.701, HL 0.830, SL 0.822, EL 0.234, ML 1.217, CI 84, SI 99.

Measurements (n=9): HW 0.662-0.706, HL 0.799-0.859, SL 0.786-0.876, EL 0.222-0.259, ML 1.159-1.253, CI 82-85, SI 98-102.

Palp formula 3,2; mandible with large apical and subapical teeth, 7-9 smaller basal teeth of uniform size and spacing; dorsal surface of mandible smooth and shiny; clypeus convex, bulging medially but not obscuring anterior clypeal margin in full-face view; anterior clypeal margin projecting and somewhat angular; occipital carina forming a distinct rim visible in full-face view, anterior ends extending a short distance onto ventral surface of head, not much beyond level of foramen; face, clypeus, and ventral surface of head smooth and shiny, piligerous puncta very small, resulting in overall smooth and highly polished appearance; mesosoma smooth and shiny throughout, with a few short, coarse carinae on posterior margin of katepisternum, a few longitudinal carinae over metapleural gland; foraminal carina absent, dorsal metapleural lobe curves slightly onto posterior face of propodeum but ends abruptly; petiole and postpetiole smooth and shining; ventral margin of petiole flat, with a low transverse flange anteriorly that forms a blunt tooth in lateral view, a few faint transverse costulae variably present immediately posterior to anterventral tooth; ventral margin of postpetiole with a thin transverse costa anteriorly, a shallowly convex lobe, and 2-3 transverse costulae posteriorly; gaster smooth and shining; all dorsal body surfaces and appendages with abundant flexuous setae; color dark red brown.

Queen and male unknown.
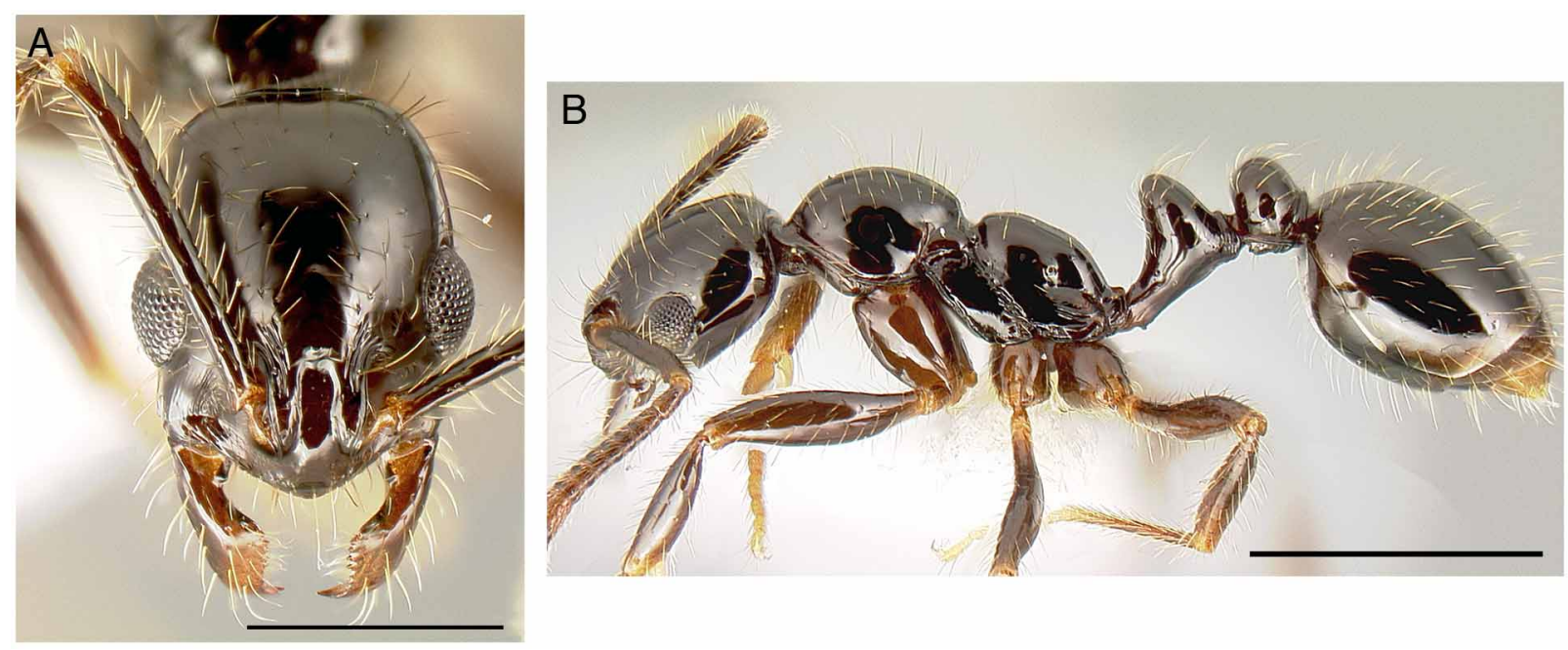

FIGURE 10. Megalomyrmex nocarina. A. Holotype worker, face view. B. Same, lateral view. Scale bar on face view $=0.5 \mathrm{~mm}$, on lateral view $=1.0 \mathrm{~mm}$.

Biology. Megalomyrmex nocarina occurs in mature wet forest habitats of the Atlantic slope of Costa Rica. It occurs from near sea level to $1110 \mathrm{~m}$ elevation. It is known exclusively as isolated workers in Winkler samples of forest floor litter.

Etymology. The name of this species refers to the lack of a foraminal carina. It is a noun in apposition and invariant.

Comments. This species is very easy to confuse with mondabora and mondaboroides, but the lack of a strong foraminal carina is reliably diagnostic. Also, the basal mandibular teeth are slightly larger and fewer in number. The nesting and feeding habits of nocarina remain to be discovered, but the similarity to mondabora and mondaboroides suggest that nocarina, too, might be a specialized predator or social parasite of Attini. 
Additional material examined. COSTA RICA: Alajuela: Casa Eladio, Rio Penas Blancas, $10^{\circ} 19^{\prime} \mathrm{N}$, $084^{\circ} 43^{\prime} \mathrm{W}, 800 \mathrm{~m}$, primary wet forest, 26 Apr 1987 (J. Longino); Laguna, Penas Blancas Valley, $10^{\circ} 20^{\prime} \mathrm{N}$, 084 $43^{\prime} \mathrm{W}, 1000 \mathrm{~m}$, wet forest, 29 Apr 1988 (J. Longino); Guanacaste: Estacion Pitilla, Guanacaste Cons. Area, $10^{\circ} 59^{\prime} \mathrm{N}, 085^{\circ} 26^{\prime} \mathrm{W}, 700 \mathrm{~m}, 24 \mathrm{Jan} 1991$ (J. Longino); Heredia: $16 \mathrm{~km} \mathrm{~N}$ Vol. Barba, $10^{\circ} 16^{\prime} \mathrm{N}, 084^{\circ} 05^{\prime} \mathrm{W}, 1020 \mathrm{~m}$, 9 Jul 1986 (J. Longino).

\section{Megalomyrmex reina Longino, new species}

(Fig. 11A-D)

Type material. Holotype queen. COSTA RICA, Alajuela: Rio Peñas Blancas, $10^{\circ} 19^{\prime} \mathrm{N} 84^{\circ} 43^{\prime} \mathrm{W}, 800 \mathrm{~m}, 2 \mathrm{Mar}$ 2004 (J. Longino\#5278-s) [MCZ, unique specimen identifier JTLC000005356]. Paratype queen: same as holotype except 4 Mar 2008 (J. Longino\#6182.2) [CAS, JTLC000007217].

Geographic range. Costa Rica.

Diagnosis. Mandible with large apical tooth and 5-6 smaller basal teeth; dorsal surface of mandible striate; ventral margin of petiole with large translucent longitudinal flange, ventral margin of flange erose, with irregular jagged posteriorly-directed teeth; ventral margin of postpetiole with large, acute anteroventral tooth.

Description. Queen. Measurements (holotype): HW 0.833, HL 0.872, SL 0.926, EL 0.276, ML 1.519, CI 96, SI 106.

Measurements (paratype): HW 0.853, HL 0.874, SL 0.928, EL 0.294, ML 1.579, CI 98, SI 106.
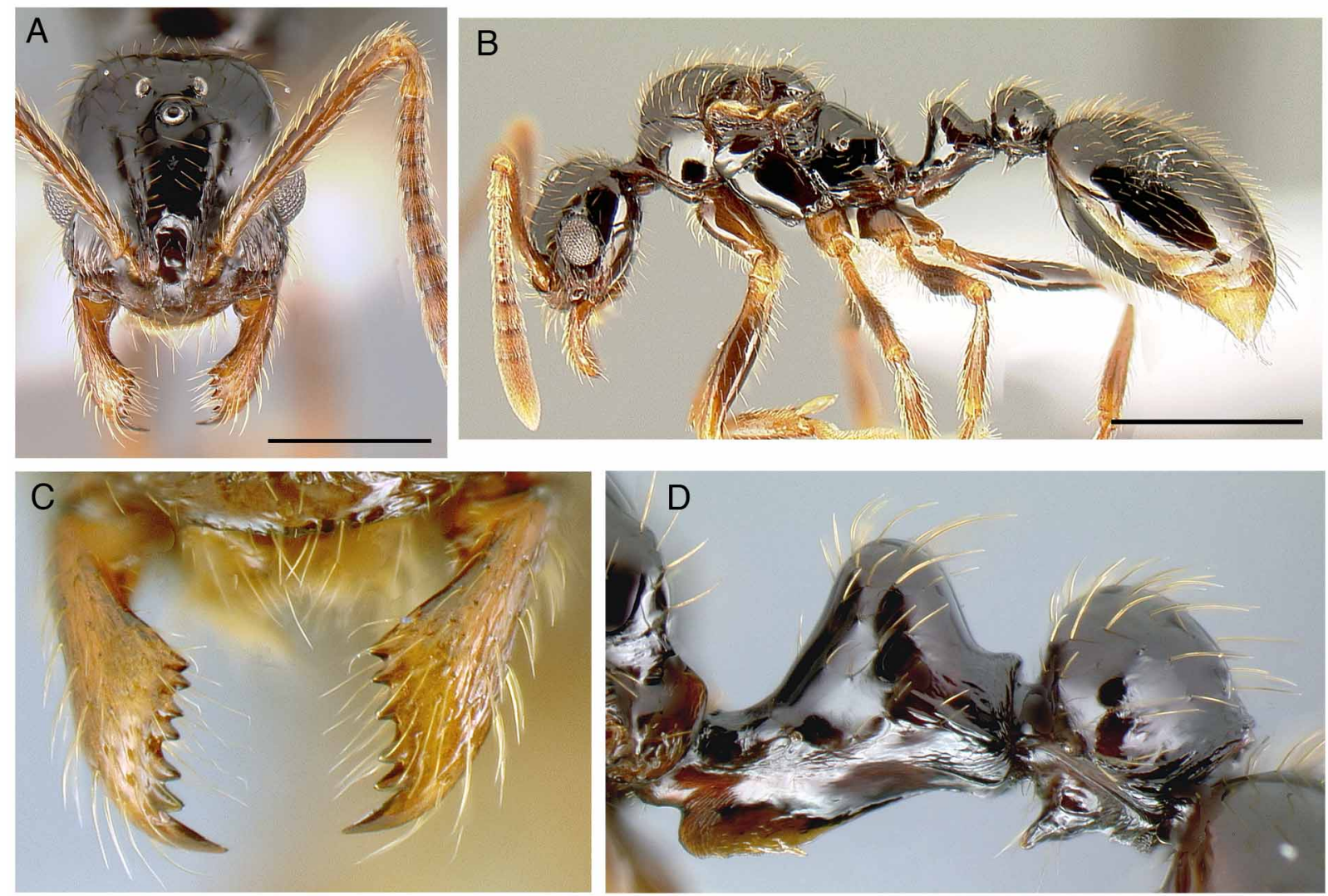

FIGURE 11. Megalomyrmex reina. A. Holotype queen, face view. B. Same, lateral view. C. Mandible. D. Petiole and postpetiole, lateral view. Scale bar on face view $=0.5 \mathrm{~mm}$, on lateral view $=1.0 \mathrm{~mm}$.

Palp formula 3,2; mandible with large apical tooth and 5-6 smaller basal teeth that gradually decrease in size (holotype has 5 basal teeth on one mandible, 6 on the other); dorsal surface of mandible faintly striate; anterior clypeal margin smoothly rounded; occipital carina thin, not visible in full-face view, anterior ends extending about $1 / 3$ to $1 / 2$ length of ventral surface of head; face, clypeus, and ventral surface of head smooth and shiny, with a few small rugulae on clypeus beneath frontal lobes and laterally, irregular rugulae on malar space between eye and 
mandibular insertion, and a few concentric rugae around antennal fossa, piligerous puncta very small, resulting in overall smooth and highly polished appearance; mesosoma smooth and shiny throughout, with longitudinal carinae on metapleuron and a few longitudinal carinae over metapleural gland; notauli fused and barely visible on anterior mesonotum; parapsidal lines distinct, extending about half length of mesonotum; dorsal and posterior faces of propodeum more or less flat, meeting at a low boss; foraminal carina incomplete, curving from metapleural lobes onto posterior face of propodeum but nearly effaced medially; petiole and postpetiole smooth and shining; petiole with short posterior peduncle; ventral margin of petiole with large translucent longitudinal flange, ventral margin of flange erose, with irregular jagged posteriorly-directed teeth (detail of margin varies between holotype and paratype); ventral margin of postpetiole with large, acute anteroventral tooth; gaster smooth and shining; all dorsal body surfaces and appendages with abundant moderately coarse setae; color dark red brown.

Biology. Both queens were collected in the same locality, in mature montane wet forest. The holotype queen was in a Winkler sample of sifted leaf litter. The paratype queen was collected as a forager on the ground. The foraging queen had rapid wasp-like behavior, with rapidly vibrating antennae.

Etymology. The name of this species refers to the fact that it is known only from queens. It is a noun in apposition and invariant.

Comments. The lack of associated workers, in spite of abundant collecting (including many Winkler samples) at the type locality, raises the possibility that this species is a workerless social parasite. Alternatively, workers may be subterranean associates of attines and thus not acccessible to standard collection techniques.

The mandibular dentition of reina is highly distinctive and unlike any other Megalomyrmex species. In other species the dentition varies from a condition of few teeth that gradually decrease in size basally to one in which the two apical teeth are much larger than a series of diminished basal denticles. In contrast, reina has a single large apical tooth, which is long and sharp, followed by a relatively uniform series of smaller teeth. The size difference between the apical and subapical tooth is much greater than in other species. Many socially parasitic ant species have falcate mandibles associated with their ability to attack and subdue hosts. Perhaps the long apical tooth of reina is such an adaptation, strengthening the conjecture that it may be a social parasite.

\section{Megalomyrmex silvestrii Wheeler}

(Fig. 1F)

Megalomyrmex silvestrii Wheeler,1909: 235. Holotype worker: Cordoba, Veracruz, Mexico [MCZ] (not examined). Senior synonym of brasiliensis, langi, misionensis, sjostedti, wheeleri: Kempf \& Brown, 1968: 97. Full synonymy in Kempf \& Brown, 1968. See also: Brandão, 1990: 443.

Measurements. Worker: HW 0.60-0.73, HL 0.71-0.88, SL 0.83-1.08, ML 1.08-1.45 (n=30, from Brandão, 1990). Geographic range. Widespread in the mainland Neotropics from Mexico to northern Argentina.

Biology. This species occurs in moist to wet forest habitats, from sea level to $1100 \mathrm{~m}$ elevation. It nests in small chambers in rotten wood or opportunistically in other small cavities in the soil. Colonies have been found in small attine nests and alone, suggesting it is a facultative predator of small Attini. Mann (1916) stated "A good series of workers were taken at Ceiba and San Juan Pueblo, nesting in the ground and in rotten logs. It is a timid species and very active when disturbed." Weber (1940) reported three collections of silvestrii (reported as wheeleri; wheeleri synonymized with silvestrii by Kempf \& Brown 1968) in nests of Cyphomyrmex costatus on Barro Colorado Island, Panama. In one nest he found a dealate queen. In a second nest he found a dealate queen and a worker. In a third nest he found 3 dealate queens and 55 workers. However, Brown (in Kempf \& Brown 1968) reported finding four nests, two from Barro Colorado Island, one from Cerro Campana, Panama, and one from Santa Teresa, Brazil, that "were nesting independently of other ants so far as he could tell." Brown's two Barro Colorado nests were "inside a small clod of soil in the leaf litter," and "in a small piece of rotten wood, $10 \mathrm{~mm}$ deep and $15 \mathrm{~mm}$ wide, also contained many termites." Diniz collected isolated nests of silvestrii in Betim, MG, Brazil (reported in Brandão 1990). Kempf and Brown (1968) suggested that the species is "not so much a parasite as it is a mass-foraging predator that specializes in raiding, and sometimes occupying, the nests of small Attini." Workers are moderately abundant in Winkler samples of forest floor litter, and workers may visit baits on the forest floor.

Material examined. BOLIVIA: Covendo, 1921-1922 (W. M. Mann); BRAZIL: Paraná: Pinhão UHE Rib. Estreito, 20 Mar 1992 (Rocha \& Barreto); Sao Paulo: Mirassol, 3 Jan 1980 (Diniz \& Almeida); COLOMBIA: 
Magdalena: Tayrona National Park, Cañaveral, $11^{\circ} 19^{\prime} \mathrm{N}, 073^{\circ} 56^{\prime} \mathrm{W}, 200 \mathrm{~m}$, dry forest, 11 Aug 1985 (J. Longino); El Recuerdo, $3 \mathrm{~km} \mathrm{SE} \mathrm{Minca,} 11^{\circ} 08^{\prime} \mathrm{N}, 074^{\circ} 06^{\prime} \mathrm{W}, 1050 \mathrm{~m}$, wet forest, 13 Aug 1985 (J. Longino); COSTA RICA: Guanacaste: Bosque Humedo, Santa Rosa Nat. Park, 10 $51^{\prime} \mathrm{N}, 085^{\circ} 37^{\prime} \mathrm{W}, 300$ m, 12 Jul 1985 (J. Longino); Heredia: La Selva Biological Station, 10²4'59"N, 08401'12"W, 50 m, mature wet forest, 14 Jun 2004 (M Molina,

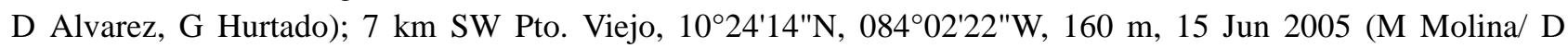

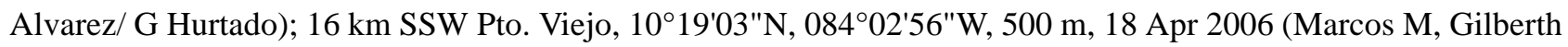
H, Felix C); $11 \mathrm{~km}$ SE La Virgen, $10^{\circ} 20^{\prime} \mathrm{N}, 084^{\circ} 04^{\prime} \mathrm{W}, 500 \mathrm{~m}$, montane wet forest, 14 Feb 2003 (ALAS); $16 \mathrm{~km}$ SSE La Virgen, $10^{\circ} 16^{\prime} \mathrm{N}, 084^{\circ} 05^{\prime} \mathrm{W}, 1100 \mathrm{~m}, 19-22$ Mar 2001 (ALAS); Limón: Hitoy Cerere Biol. Reserve, $09^{\circ} 40^{\prime} \mathrm{N}, 083^{\circ} 02^{\prime} \mathrm{W}, 500 \mathrm{~m}, 30$ Aug 1985 (J. Longino); Puntarenas: Sirena, Corcovado National Park, $08^{\circ} 29^{\prime} \mathrm{N}$, 0833' W, 5 m, 18 Dec 1990 (J. Longino); 13 km SSW Pto. Jimenez, 08²4'24"N, 083¹9'42"W, 130 m, tropical rainforest, 10 Mar 2008 (J. Longino); 15 km SSW Pto. Jimenez, 08²4'29"N, 083 ${ }^{\circ} 19^{\prime} 39^{\prime \prime} \mathrm{W}, 170 \mathrm{~m}$, mature wet

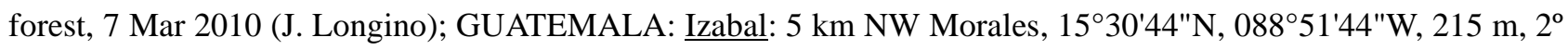

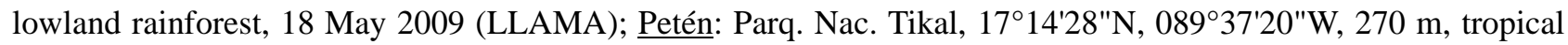

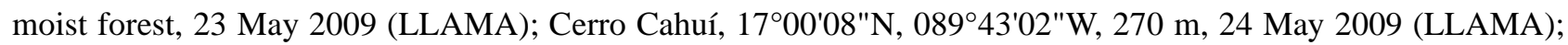
13 km NW Machaquilá, 16²6'47"N, 089 32'56"W, 400 m, 27 May 2009 (LLAMA); Zacapa: 8.5 km NE Tuculután, $15^{\circ} 03^{\prime} 31^{\prime \prime N}, 089^{\circ} 40^{\prime} 35^{\prime \prime} \mathrm{W}, 1100 \mathrm{~m}$, pine oak forest, 6 Jul 2007 (M. Branstetter); HONDURAS: Atlantida, San Juan Pueblo, $15^{\circ} 35^{\prime} \mathrm{N}, 087^{\circ} 14^{\prime} \mathrm{W}$ (W. M. Mann); MEXICO: Chiapas: $8 \mathrm{~km}$ SE Salto de Agua, $17^{\circ} 30^{\prime} 53^{\prime \prime N}, 092^{\circ} 17^{\prime} 56 " \mathrm{~W}, 100 \mathrm{~m}, 2^{\circ}$ wet forest, 16 Jun 2008 (M. Branstetter); Playón de la Gloria, 1609'33"N, $090^{\circ} 54^{\prime} 06^{\prime \prime W}, 160 \mathrm{~m}$, lowland wet forest, 26 Jun 2008 (LLAMA); $21 \mathrm{~km}$ SW Salto de Agua, 17 $23^{\prime} 08^{\prime \prime} \mathrm{N}$,

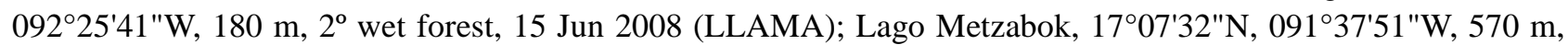
lowland wet forest, 6 Jun 2008 (LLAMA); Nahá, 16 $566^{\prime} 56^{\prime \prime} \mathrm{N}, 091^{\circ} 35^{\prime} 42^{\prime \prime} \mathrm{W}, 930 \mathrm{~m}$, mesophil forest, 8 Jun 2008 (LLAMA); VENEZUELA: Aragua: Ocumares de la Costa, 10²7'36"N, 067 $46^{\prime} 35^{\prime \prime} \mathrm{W}, 70 \mathrm{~m}$, secondgrowth dry forest, 13 Aug 2008 (J. Longino).

\section{Megalomyrmex symmetochus Wheeler}

(Figs 1B, 3A, 3C)

Megalomyrmex symmetochus Wheeler, W.M. 1925: 168, fig. 5. Lectotype worker (designated by Brandão, 1990: 445): Barro Colorado Island, Panama, July 1924 (Wheeler) [MCZ] (not examined). Wheeler,1925: 168, description of queen, male. Wheeler, G. \& Wheeler, J., 1955: 126, description of larva. See also: Brandão, 1990: 445.

Measurements. Worker: HW 0.60-0.84, HL 0.75-0.89, SL 0.72-0.82, EL 0.21-0.25, ML 1.03-1.31, CI 88-95, SI 90-93 ( $\mathrm{n}=30$, from Brandão, 1990; $n=5$, current study).

Geographic range. Costa Rica to Panama.

Biology. This species appears to be a specialized associate of small Attini (Wheeler 1925, Brandão 1990, Adams et al. 2000), a habit shared with other species of Megalomyrmex such as wettereri, mondabora, and adamsae. As defined here, M. symmetochus specializes on Sericomyrmex amabilis Wheeler. Wheeler (1925) found numerous colonies nesting with Sericomyrmex on Barro Colorado Island, Panama. He observed a number of colonies in the lab, and made the following observations (in Wheeler's account M. symmetochus is referred to as Cepobroticus Wheeler, a subgenus erected by Wheeler to contain the single species M. symmetochus, later synonymized with Megalomyrmex by Ettershank [1966]):

"The colonies of the Cepobroticus so frequently found living with Sericomyrmex amabilis were decidedly less populous than those of their host. The largest comprised less than 75 individuals, and often the number did not exceed 40 or 50 . In every nest a dealated mother queen was present. She usually took up her station, surrounded by a group of her workers, in one of the crypts of the fungus garden a short distance - half to three quarters of an inch - from the Sericomyrmex queen. The guest ants kept their brood in small clusters scattered through the garden and each cluster was cared for by a few workers. Although the ants and their brood were thus intermingled, the workers of each species lavished their attention exclusively on their own eggs, larvae and pupae and were never seen even to transport the progeny of the other species from one part of the garden to another.

The workers and queens of Cepobroticus are rather alert and move about more rapidly than their hosts. They devote so much time to licking and fondling one another that the observer is somewhat astonished to find 
them paying little or no attention to the fungus-growers. As a rule the two species are indifferent to one another. One may watch them for hours without observing anything more than rather distant, mutual antennal salutations. On rare occasions a worker Cepobroticus may be seen licking the gaster of a Sericomyrmex worker or of the sluggish queen. More frequently one of the host workers may be observed in the act of lavishing similar but more elaborate attentions on a Cepobroticus worker. The fungus-grower begins by licking the feet or tarsi, the tibiae and femora, then the thorax or abdomen and finally the head and even the mandibles of the guest. During this operation the latter remains motionless and inclines its body somewhat to one side.

The Sericomyrmex never feed their guests by regurgitation. This is not surprising because they never feed one another thus, but resort individually to the growing fungus bromatia. When hungry the Cepobroticus workers and queen also crop the fungus mycelium, but they do this rather roughly, using their mandibles and even shaking or disturbing the substratum. The guests very rarely transport or rearrange the particles of the substratum or take the slightest interest in the garden, except as a source of nourishment. Only on one occasion did I see a Cepobroticus carry a particle of the substratum to another spot, insert it and pat it down with her fore feet. When fresh fruit was introduced into the nest, it was much less frequently visited and eaten by the guests than by their hosts."

Numerous collections from Pipeline Road and vicinity (Panama) by R. Adams and colleagues have all been from nests of Sericomyrmex amabilis. At La Selva Biological Station in Costa Rica, alate queens and males have been collected at blacklights. Males and queens were common at the lab clearing blacklight on 4 Aug 1992. A lone worker was obtained by Ronald Vargas, during general collection of ants from trail surfaces and low vegetation.

Material examined. COSTA RICA: Heredia: La Selva Biological Station, $10^{\circ} 26^{\prime} \mathrm{N}, 084^{\circ} 01^{\prime} \mathrm{W}, 50 \mathrm{~m}, 1$ May

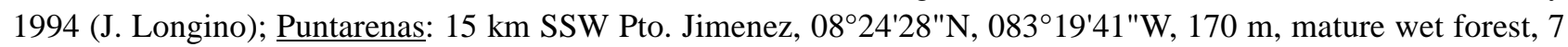
Mar 2010 (J. Longino); PANAMA: Canal Zone: Pipeline Road, 0909'36"N, 07944'42"W, 50 m, wet forest, 29 Jul 2005 (R. Adams); Barro Colorado Island, 0909'N, 07951'W, 100 m, 12 Dec 2003.

\section{Megalomyrmex wallacei Mann}

(Fig. 2A)

Megalomyrmex wallacei Mann, 1916: 445, pl. 3, fig. 28. Lectotype queen (designated by Brandão 1990: 426): Porto Velho, Rondonia, Brazil [MCZ] (not examined). Paralectotype worker: same data [MZSP] (not examined). Brandão, 2003: 150, description of male. See also: Brandão, 1990: 426.

Measurements. Worker: HW 0.98-1.03, HL 1.13-1.18, SL 1.50-1.58, ML 1.78-1.85 (n=30, from Brandão, 1990). Geographic range. Brazil (Amazonas, Rondonia, Pará, Tocantins), Guyana, Colombia, Costa Rica (Brandão 1990, 2003).

Biology. This species occurs in mature wet forest, usually low-elevation rainforest. Brandão (2003) reports the species nesting under leaves on the forest floor, in colonies of up to 300 workers. In Costa Rica, workers have been collected at baits on the forest floor, and one nest was observed at La Selva Biological Station. It was inside a $6 \mathrm{~cm}$ long rotten cacao pod on the trunk of a cacao tree. The nest contained 93 workers. There was no morphologically distinct queen, but there was abundant brood of all sizes, from eggs to pupae. The workers showed considerable size variation, and larger workers had an enlarged mesonotum.

Material examined. COSTA RICA: Heredia: La Selva Biological Station, $10^{\circ} 26^{\prime} \mathrm{N}, 084^{\circ} 01^{\prime} \mathrm{W}, 50 \mathrm{~m}, 29 \mathrm{Jul}$ 1995 (J. Longino); Puntarenas: Los Planes, Corcovado National Park, 08³8'N, 083² 40'W, 100 m, 4 Dec 1981 (J.

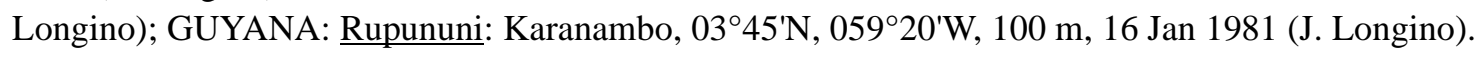

\section{Megalomyrmex wettereri Brandão}

Megalomyrmex wettereri Brandão, 2003: 155, figs 1-4. Holotype worker: La Selva, $10^{\circ} 26^{\prime} \mathrm{N} 84^{\circ} 01^{\prime} \mathrm{W}, 50-150 \mathrm{~m}$, Heredia Prov., Costa Rica, 2 Mar 1993 (Wetterer) [MCZ] (paratypes examined). Paratype queen: km 7 of El Llano Carti Suitupo Road, Panama, 7 Jun 1998 (U. Mueller 980607-01) [MZSP] (not examined).

Megalomyrmex sp. nov.: Adams et al. 2000: 549-554. 
Measurements. Worker: HW 0.523, HL 0.588, SL 0.497, EL 0.076, ML 0.817, CI 89, SI 85 (n=1, present study, from same nest series as holotype).

Geographic range. Costa Rica, Panama.

Biology. Megalomyrmex wettereri is known from two lowland rainforest sites: Barro Colorado Island in Panama and La Selva Biological Station in Costa Rica. Observations from Barro Colorado were the subject of Adams et al. (2000). Colonies of M. wettereri were found occupying abandoned nests of Cyphomyrmex longiscapus Weber. The fungus gardens of the Cyphomyrmex Mayr were intact and the Megalomyrmex workers were observed feeding on the fungal symbiont. When lab colonies of $M$. wettereri were placed in contact with colonies of $C$. longiscapus, the $M$. wettereri aggressively attacked, killing the adult workers. When presented with Cyphomyrmex larvae, they stripped them of their fungal coating and fed them to their own larvae. Adams et al. concluded that $M$. wettereri was an "agro-predator," raiding Cyphomyrmex colonies en masse, displacing the Cyphomyrmex workers, and feeding on the remaining brood and fungi.

The holotype series was a colony collected by Jim Wetterer at La Selva. He found the colony inhabiting a nest of Trachymyrmex cornetzi (Forel) (Brandão 2003 identified the attine as T. bugnioni (Forel); I identify this common La Selva attine as T. cornetzi).

\section{Acknowledgments}

Rachelle Adam's devotion to Megalomyrmex biology and her discovery of cryptic species associated with attines was the inspiration for this paper. Loans of museum specimens were provided by Stefan Cover (MCZ). Taxonomic catalogue resources were provided by Barry Bolton, by Donat Agosti and Norm Johnson (Hymenoptera Name Server), and by Brian Fisher (AntWeb). As usual, James Trager was my consultant on the construction of scientific names. Phil Ward tested the key and made improvements on the manuscript. This work was supported by National Science Foundation grants DEB-0072702 (Project ALAS) and DEB-0640015 (Project LLAMA), National Geographic Society grants 7331-02 and 7751-04, and Conservation International (TEAM project).

\section{References}

Adams, R.M.M. \& Longino, J.T. (2007) Nesting biology of the arboreal fungus-growing ant Cyphomyrmex cornutus and behavioral interactions with the social-parasitic ant Megalomyrmex mondabora. Insectes Sociaux. 54, $136-143$.

Adams, R.M.M., Mueller, U.G., Schultz, T. R. \& Norden, B. (2000) Agro-predation: usurpation of attine fungus gardens by Megalomyrmex ants. Naturwissenschaften. 87, 549-554.

Ashmead, W.H. (1905) Additions to the recorded Hymenopterous fauna of the Philippine Islands, with descriptions of new species. Proceedings of the United States National Museum, 28, 957-971.

Bolton, B. (1987) A review of the Solenopsis genus-group and revision of Afrotropical Monomorium Mayr (Hymenoptera: Formicidae). Bulletin of the British Museum (Natural History), Entomology, 54, 263-452.

Bolton, B. (1994) Identification Guide to the Ant Genera of the World. Harvard University Press, Cambridge, MA, London, 222 pp.

Bolton, B. (2003) Synopsis and classification of Formicidae. Memoirs of the American Entomological Institute, 71, 1-370.

Borgmeier, T. (1930) Duas rainhas de Eciton e algumas outras formigas brasileiras. Archivos do Instituto Biologico, 3, $21-40$.

Brandão, C.R.F. (1990) Systematic revision of the Neotropical ant genus Megalomyrmex Forel (Hymenoptera: Formicidae: Myrmicinae), with the description of thirteen new species. Arquivos de Zoologia, São Paulo, 31, 411-481.

Brandão, C.R.F. (2003) Further revisionary studies on the ant genus Megalomyrmex Forel (Hymenoptera: Formicidae: Solenopsidini). Papéis Avulsos de Zoologia, 43, 145-159.

Dalla Torre, C.G., de. (1893) Catalogus Hymenopterorum hucusque descriptorum systematicus et synonymicus. Volumen 7. Formicidae (Heterogyna). Sumptibus Guilelmi Engelmann, Lipsiae [Leipzig], I-VIII + 1-289 pp.

Dlussky, G.M. \& Fedoseeva, E.B. (1988) Proiskhozhdenie i rannie etapy evolyutsii murav'ev [Origin and early evolution of ants]. In: Ponomarenko, A.G. (Ed), Melovoy Biotsenoticheskiy Krizis i Evolyutsiya Nasekomykh [Cretaceous Biocoenotic Crisis and evolution of the insects]. Nauka, Moskva, pp. 70-144. (In Russian).

Emery, C. (1890) Studii sulle formiche della fauna neotropica. Bullettino della Società Entomologica Italiana, 22 , 38-80.

Emery, C. (1895) Die Gattung Dorylus Fab. und die systematische Eintheilung der Formiciden. Zoologische Jahrbücher. Abtheilung für Systematik, Geographie und Biologie der Thiere, 8, 685-778.

Emery, C. (1896) Studi sulle formiche della fauna neotropica. XVII-XXV. Bullettino della Società Entomologica Italiana, 28, 
33-107.

Emery, C. (1914) Intorno alla classificazione dei Myrmicinae. Rendiconto delle Sessioni della R. Accademia delle Scienze dell'Istituto di Bologna (N.S.), 18, 29-42.

Emery, C. (1922) Hymenoptera, Fam. Formicidae, subfam. Myrmicinae. In: Wytsman, P. Genera Insectorum. Bruxelles, Fasc. 174B, 95-206.

Ettershank, G. (1966) A generic revision of the world Myrmicinae related to Solenopsis and Pheidologeton (Hymenoptera: Formicidae). Australian Journal of Zoology, 14, 73-171.

Fernández, F. \& Baena, M. L. (1997) Hormigas de Colombia VII: nuevas especies de los géneros Lachnomyrmex Wheeler y Megalomyrmex Forel (Hymenoptera: Formicidae). Caldasia, 19, 109-114.

Forel, A. (1885 ["1884"]) Etudes myrmécologiques en 1884; avec une description des organes sensoriels des antennes. Bulletin de la Société Vaudoise des Sciences Naturelles, 20, 316-380.

Forel, A. (1899) Formicidae. [part c]. Biologia Centrali-Americana, Hymenoptera, 3, 57-80.

Forel, A. (1917) Cadre synoptique actuel de la faune universelle des fourmis. Bulletin de la Société Vaudoise des Sciences Naturelles, 51, 229-253.

Hölldobler, B. \& Wilson, E.O. (1990) The Ants. Harvard University Press, Cambridge, MA, 732 pp.

Jaffe, K. (1993) El mundo de las hormigas. Equinoccio: Ediciones de la Universidad Simón Bolívar, Baruta, 188 pp.

Jones, T.H., Blum, M.S., Fales, H.M., Brandão, C.R.F. \& Lattke, J.E. (1991a). Chemistry of venom alkaloids in the ant genus Megalomyrmex. Journal of Chemical Ecology, 17, 1897-1908.

Jones, T.H., DeVries, P.J. \& Escoubas, P. (1991b). Chemistry of venom alkaloids in the ant Megalomyrmex foreli (Myrmicinae) from Costa Rica. Journal of Chemical Ecology, 17, 2507-2518.

Jones, T.H., Wojciechowski, T.J., Snelling, R.R., Torres, J.A., Chacon, P. \& DeVries, P.J. (1999) Dialkylpyrrolidines from the ants Megalomyrmex cyendyra Brandão and M. latreillei Emery. Caribbean Journal of Science, 35, 310-311.

Kempf, W.W. (1961) A survey of the ants of the soil fauna in Surinam (Hymenoptera: Formicidae). Studia Entomologica, 4, 481-524.

Kempf, W.W. (1970) Taxonomic notes on ants of the genus Megalomyrmex Forel, with the description of new species (Hymenoptera, Formicidae). Studia Entomologica, 13, 353-364.

Kempf, W.W. \& Brown, W.L.Jr. (1968) Report on some Neotropical ant studies. Papéis Avulsos de Zoologia (São Paulo), 22, 89-102.

Kusnezov, N. (1952 ["1951"]) El género Pheidole en la Argentina. Acta Zoologica Lilloana, 12, 2-88.

Kusnezov, N. (1957) Die Solenopsidinen-Gattungen von Südamerika. Zoologischer Anzeiger, 158, 266-280.

Kusnezov, N. (1962) Una nueva especie del género Brownidris Kusnezov. Acta Zoologica Lilloana, 18, $155-161$.

Kusnezov, N. (1964 ["1963"]) Zoogeografia de las hormigos en Sudamerica. Acta Zoologica Lilloana, 19, $25-186$.

Mann, W.M. (1916) The ants of Brazil. (The Stanford Expedition to Brazil, 1911, John C. Branner, Director). Bulletin of the Museum of Comparative Zoology, 60, 399-490.

Mann, W.M. (1922) Ants from Honduras and Guatemala. Proceedings of the United States National Museum, 61, 1-54.

Santschi, F. (1936) Fourmis nouvelles ou intéressantes de la République Argentine. Revista de Entomologia, 6, $402-421$.

Smith, M.R. (1947) A new species of Megalomyrmex from Barro Colorado Island, Canal Zone (Hymenoptera, Formicidae). Proceedings of the Entomological Society of Washington, 49, 101-103.

Weber, N.A. (1940) The biology of the fungus-growing ants. Part VI. Key to Cyphomyrmex, new Attini and a new guest ant. Revista de Entomologia (Rio de Janeiro), 11, 406-427.

Weber, N.A. (1941) The biology of the fungus-growing ants. Part VII. The Barro Colorado Island, Canal Zone, species. Revista de Entomologia (Rio de Janeiro), 12, 93-130.

Wheeler, G.C. \& Wheeler, J. (1955) The ant larvae of the myrmicine tribe Solenopsidini. American Midland Naturalist, 54 , 119-141.

Wheeler, W.M. (1909) Ants collected by Prof. F. Silvestri in Mexico. Bollettino del Laboratorio di Zoologia Generale e Agraria della Reale Scuola Superiore d'Agricoltura. Portici, 3, 228-238.

Wheeler, W.M. (1910) Ants, their structure, development and behaviour. Columbia University Biological Series 9, New York, $663 \mathrm{pp}$.

Wheeler, W.M. (1911) A list of the type species of the genera and subgenera of Formicidae. Annals of the New York Academy of Sciences, 21, 157-175.

Wheeler, W.M. (1922) The ants of the Belgian Congo. Bulletin of the American Museum of Natural History, 45, 1-1139.

Wheeler, W.M. (1925) A new guest-ant and other new Formicidae from Barro Colorado Island, Panama. Biological Bulletin (Woods Hole), 49, 150-181. 